\title{
Application of the Statistical Oxidation Model (SOM) to Secondary Organic Aerosol formation from photooxidation of $\mathrm{C}_{12}$ alkanes
}

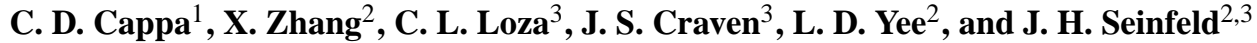 \\ ${ }^{1}$ Department of Civil and Environmental Engineering, University of California, Davis, CA, 95616, USA \\ ${ }^{2}$ Division of Engineering and Applied Science, California Institute of Technology, Pasadena, CA, 91125, USA \\ ${ }^{3}$ Division of Chemistry and Chemical Engineering, California Institute of Technology, Pasadena, CA, 91125, USA \\ Correspondence to: C. D. Cappa(cdcappa@ucdavis.edu) and J. H. Seinfeld (seinfeld@caltech.edu)
}

Received: 14 September 2012 - Published in Atmos. Chem. Phys. Discuss.: 15 October 2012

Revised: 23 January 2013 - Accepted: 25 January 2013 - Published: 8 February 2013

\begin{abstract}
Laboratory chamber experiments are the main source of data on the mechanism of oxidation and the secondary organic aerosol (SOA) forming potential of volatile organic compounds. Traditional methods of representing the SOA formation potential of an organic do not fully capture the dynamic, multi-generational nature of the SOA formation process. We apply the Statistical Oxidation Model (SOM) of Cappa and Wilson (2012) to model the formation of SOA from the formation of the four $\mathrm{C}_{12}$ alkanes, dodecane, 2methyl undecane, cyclododecane and hexylcyclohexane, under both high- and low- $\mathrm{NO}_{\mathrm{x}}$ conditions, based upon data from the Caltech chambers. In the SOM, the evolution of reaction products is defined by the number of carbon $\left(N_{\mathrm{C}}\right)$ and oxygen $\left(N_{\mathrm{O}}\right)$ atoms, and the model parameters are (1) the number of oxygen atoms added per reaction, (2) the decrease in volatility upon addition of an oxygen atom and (3) the probability that a given reaction leads to fragmentation of the molecules. Optimal fitting of the model to chamber data is carried out using the measured SOA mass concentration and the aerosol O:C atomic ratio. The use of the kinetic, multi-generational SOM is shown to provide insights into the SOA formation process and to offer promise for application to the extensive library of existing SOA chamber experiments that is available.
\end{abstract}

\section{Introduction}

Organic aerosol (OA) comprises a major fraction of the atmospheric sub-micron aerosol burden (Zhang et al., 2007; Jimenez et al., 2009), and the dominant portion of OA is formed from condensation of oxidation products of gasphase reactions of volatile organic compounds, termed secondary organic aerosol (SOA). The extent to which a given parent organic compound forms SOA depends on a variety of factors, including the carbon chain length, structure and reactivity, as well as external factors such as temperature, the abundance of $\mathrm{NO}_{\mathrm{x}}\left(=\mathrm{NO}+\mathrm{NO}_{2}\right)$ and the identity of the oxidant $\left(\mathrm{OH}, \mathrm{O}_{3}, \mathrm{NO}_{3}\right)$ (Kanakidou et al., 2005). Additionally, the properties of the SOA, e.g. hygroscopicity, volatility and atomic composition, depend on all of the above factors (Jimenez et al., 2009).

Understanding SOA formation via photooxidation (i.e. reactions with $\mathrm{OH}$ ) presents a unique challenge in that not only is the precursor SOA species (i.e. the parent organic) reactive towards $\mathrm{OH}$, but so are the oxidation products. The extent to which each generation of products contributes directly to SOA formation depends intimately on the details of the atmospheric chemistry for the particular organic. Laboratory chamber experiments are the main source of data on the mechanism of oxidation and the SOA forming potential of a parent organic. Because SOA forms via gas-particle partitioning, the amount of SOA depends on the mass of absorbing material in the aerosol phase, in addition to the unique chemistry. For comparison of SOA formation from different organics, especially in atmospheric models, an SOA model is required. Traditional methods of representing the SOA formation potential, or yield, of an organic do not fully capture the dynamic, multi-generational nature of photooxidation, as they generally treat SOA formation as a one-step process from precursor to products. This includes both the 2-product model (Odum et al., 1996) and static volatility 
Table 1. Experimental conditions and results from photooxidation experiments.

\begin{tabular}{|c|c|c|c|c|c|c|c|}
\hline Alkane & $\begin{array}{l}{[\mathrm{HC}]_{0}} \\
(\mathrm{ppbv})\end{array}$ & $\begin{array}{l}{[\mathrm{OH}]^{\mathrm{a}}} \\
\left(\mathrm{molecules} \mathrm{cm}^{-3}\right)\end{array}$ & $\begin{array}{l}C_{\mathrm{OA}}^{\mathrm{b}} \\
\left(\mu \mathrm{g} \mathrm{m}^{-3}\right)\end{array}$ & $\begin{array}{l}\text { Yield }^{b} \\
(\%)\end{array}$ & $\begin{array}{l}\text { Yield }^{\mathrm{c}} \\
(\%)\end{array}$ & $\begin{array}{l}\mathrm{O}: \mathrm{C} \\
\max \end{array}$ & $\begin{array}{l}\mathrm{O}: \mathrm{C} \\
\min \end{array}$ \\
\hline \multicolumn{8}{|l|}{ Low $\mathrm{NO}_{\mathrm{x}}$} \\
\hline dodecane & 34.0 & $2.5 \times 10^{6}$ & 21.6 & 10.3 & 6.1 & 0.28 & 0.21 \\
\hline 2-methylundecane & 28.1 & $2.4 \times 10^{6}$ & 18.1 & 10.8 & 7.2 & 0.28 & 0.20 \\
\hline hexylcyclohexane & 15.6 & $2.95 \times 10^{6}$ & 28.9 & 29.6 & 15.4 & 0.32 & 0.22 \\
\hline cyclododecane & 9.8 & $2.7 \times 10^{6}$ & 15.8 & 24.4 & 17.2 & 0.24 & 0.15 \\
\hline \multicolumn{8}{|l|}{ High $\mathrm{NO}_{\mathrm{x}}$} \\
\hline dodecane & 32.2 & $4.5 \times 10^{7} / 1.85$ & 10.6 & 6.8 & 6.2 & 0.33 & 0.33 \\
\hline 2-methylundecane & 72.4 & $3.3 \times 10^{7} / 1.85$ & 23.5 & 7.8 & 5.1 & 0.26 & 0.26 \\
\hline hexylcyclohexane & 22.1 & $4.1 \times 10^{7} / 1.7$ & 17.5 & 16.4 & 12.3 & 0.32 & 0.32 \\
\hline cyclododecane & 13.8 & $2.7 \times 10^{7} / 0.92$ & 29.5 & 41.5 & 38.3 & 0.27 & 0.27 \\
\hline
\end{tabular}

basis-set (Donahue et al., 2006). Recently, methodologies have been developed that represent photooxidation and subsequent SOA formation within more dynamic frameworks (Aumont et al., 2005; Robinson et al., 2007; Lane et al., 2008; Barsanti et al., 2011; Valorso et al., 2011; Cappa and Wilson, 2012; Donahue et al., 2012). Depending on the specific methodology employed, these models allow for reaction of the first (and later) generation oxidation products, fragmentation and tracking of the detailed composition of the particle and gas-phase.

Here, we apply the Statistical Oxidation Model (SOM) of Cappa and Wilson (2012) to model the formation of SOA from the photooxidation of a series of $\mathrm{C}_{12}$ alkanes of varying structure, two of which are linear (dodecane and 2-methyl undecane) and two of which have ring structures (cyclododecane and hexylcyclohexane). Experiments were conducted under both high- and low- $\mathrm{NO}_{\mathrm{x}}$ conditions to explore the important influence of $\mathrm{NO}_{\mathrm{x}}$ on the SOA formation. The best-fit model is found to capture the time-evolution of the observed SOA mass concentration and, to a reasonable extent, the $\mathrm{O}: \mathrm{C}$ atomic ratio under both high- and low- $\mathrm{NO}_{\mathrm{x}}$ conditions. Bestfit SOM parameters are reported, and indicate that, per reaction with $\mathrm{OH}$, photooxidation leads to more rapid oxygen addition under high- $\mathrm{NO}_{\mathrm{x}}$ conditions than low- $\mathrm{NO}_{\mathrm{x}}$ conditions. Despite the more rapid oxygen addition under high- $\mathrm{NO}_{\mathrm{x}}$ conditions, the nature of the functional groups added lead to a smaller decrease in volatility (per oxygen added) than under low- $\mathrm{NO}_{\mathrm{x}}$ conditions. The success of fitting the SOM to these alkane SOA formation data offers promise to apply the SOM to the extensive library of existing chamber experiments that is available.

\section{Experimental methods}

Experiments were conducted in the Caltech dual $28-\mathrm{m}^{3}$ Teflon chambers. Details of the facility have been described previously (Cocker et al., 2001). Prior to each experiment, the chambers were flushed with dried, purified air for $>24$ $\mathrm{h}$, until the particle concentration was $<100 \mathrm{~cm}^{-3}$ and the volume concentration was $<0.1 \mu \mathrm{m}^{3} \mathrm{~m}^{-3}$.

For all experiments, neutral ammonium sulfate seed aerosol was used to provide surface area for condensation of the semi-volatile oxidation products. Particle size distributions were measured using a differential mobility analyser (DMA, TSI, 3081) coupled with a condensation particle counter (CPC, TSI, CNC-3760).

Photooxidation experiments were run under both high and low $-\mathrm{NO}_{\mathrm{x}}$ conditions. Low- $\mathrm{NO}_{\mathrm{x}}(<1 \mathrm{ppb})$ experiments were conducted using photolysis of $\mathrm{H}_{2} \mathrm{O}_{2}$ as the $\mathrm{OH}$ radical source. High- $\mathrm{NO}_{\mathrm{x}}$ experiments were conducted using photolysis of $\mathrm{HONO}$ as the $\mathrm{OH}$ radical source. The primary $\mathrm{NO}_{\mathrm{x}}$ source is direct photolysis of $\mathrm{HONO}$, although some $\mathrm{NO}$ and $\mathrm{NO}_{2}$ formed as part of the HONO preparation. The gas-phase concentration of the SOA precursor was measured throughout the experiments. Initial concentrations are given in Table 1. Four alkanes are considered here, each with 12 carbon atoms: dodecane $\left(\mathrm{C}_{12} \mathrm{H}_{26}\right)$, 2-methyl undecane $\left(\mathrm{C}_{12} \mathrm{H}_{26}\right)$, hexylcyclohexane $\left(\mathrm{C}_{12} \mathrm{H}_{24}\right)$ and cyclododecane $\left(\mathrm{C}_{12} \mathrm{H}_{24}\right)$.

Photooxidation was initiated by irradiating the chamber with blacklights. Output from the lights is between 300 and $400 \mathrm{~nm}$, with a maximum at $354 \mathrm{~nm}$. Importantly, HONO photolysis is efficient in this wavelength range, and thus the concentration of HONO (and $\mathrm{OH}$ ) decays towards zero over a period of $\sim 3 \mathrm{~h}$ once the lights are turned on. $\mathrm{H}_{2} \mathrm{O}_{2}$ photolysis is comparably much slower, which facilitates operation at 
a nearly constant $[\mathrm{OH}]$ throughout the low- $\mathrm{NO}_{\mathrm{x}}$ experiments. To access long oxidation times (up to $32 \mathrm{~h}$ ) in the low- $\mathrm{NO}_{\mathrm{x}}$ experiments, the methodology set out by Loza et al. (2012) was followed. As a result, the time series of OA mass concentrations $\left(C_{\mathrm{OA}}\right)$ under low- $\mathrm{NO}_{\mathrm{x}}$ conditions have a "gap" of $\sim 6$ h (typically from hours $18-24$ ).

Chemically-resolved aerosol mass concentrations were measured using an Aerodyne high-resolution time-of-flight aerosol mass spectrometer (HR-ToF-AMS, henceforth referred to as AMS). Real-time mass spectra of the particles were collected alternating between "V-mode" and "Wmode". The "V-mode" provides higher sensitivity while the "W-mode" provides higher resolution. The "W-mode" data were analysed using the software toolboxes PIKA (DeCarlo et al., 2006) and APES (Aiken et al., 2007; Aiken et al., 2008; Chhabra et al., 2010). Through consideration of ions with specific molecular formulas, as determined from the "W-mode" spectra, the elemental composition of the SOA can be determined (in particular, the O:C and $\mathrm{H}: \mathrm{C}$ atomic ratios). The estimated uncertainty in the $\mathrm{O}: \mathrm{C}$ is $\pm 30 \%$ and in the $\mathrm{H}: \mathrm{C}$ is $10 \%$.

A correction for wall loss needs to be applied to determine the SOA mass concentration. Two limiting assumptions can be employed to bound the interactions between particles deposited to the wall and vapors in the chamber. Here we use a lower bound, in which particles deposited on the wall are assumed to cease interaction with suspended vapors after deposition (Loza et al., 2012). The total organic mass deposited to the wall was calculated based on the particle numberweighted size distribution. The wall loss rates for particles of different sizes are obtained from separate characterization experiments. The deposited particle number distribution is added to the suspended particle number distribution to give a wall-loss corrected number distribution, which is then converted to a volume concentration and then mass concentration, assuming spherical particles. For the low- $\mathrm{NO}_{\mathrm{x}}$ experiments reported on here, wall loss corrections at long times require extrapolation of the $C_{\mathrm{OA}}$ across the "gap", which decreases the certainty of the correction and, as a result, the accuracy of the wall-loss corrected $C_{\mathrm{OA}}$ values after the gap. Thus, only the pre-gap $C_{\mathrm{OA}}$ data are used quantitatively here.

\section{Statistical Oxidation Model}

The statistical oxidation model (SOM) simulates the oxidation of a parent hydrocarbon and its reaction products in time, and is described in detail in Cappa and Wilson (2012). In the SOM, the evolution of the gas and particle phase composition is followed through a space in which all product species are defined solely by their number of carbon $\left(N_{\mathrm{C}}\right)$ and oxygen $\left(N_{\mathrm{O}}\right)$ atoms. Equilibrium partitioning between the gas and particle phases is assumed to hold at each time-step of the model ( $\sim 1-2 \mathrm{~min}$ ) (Pankow, 1994). It is assumed that the properties of each species (i.e. $N_{\mathrm{C}} / N_{\mathrm{O}}$ pair) can be repre- sented by some mean values that account for the actual distribution of functional groups within the group of molecules that make up an SOM species. There are a few adjustable parameters within the SOM: (1) the number of oxygen atoms added per reaction, which is represented as an array of probabilities of adding 1, 2, 3 or 4 oxygen atoms, termed $P_{\text {func }}$, (2) the decrease in volatility upon addition of an oxygen atom, termed $\triangle \mathrm{LVP}$, which is the difference in the log of the saturation concentration, $C_{\mathrm{sat}}$, per oxygen added, or

$\Delta \mathrm{LVP}=\log \left[\frac{C_{\mathrm{sat}, N_{\mathrm{O}}}}{C_{\mathrm{sat}, N_{\mathrm{O}}+1}}\right]$

and (3) the probability that a given reaction leads to fragmentation of the product molecule into two smaller molecules, termed $P_{\text {frag. }}$. Note that positive values of $\triangle$ LVP correspond to a decrease in vapour pressure upon oxygen addition. These parameters can be adjusted to determine a best fit of the model to the observations. The SOM also includes heterogeneous reactions with $\mathrm{OH}$ radicals (Cappa and Wilson, 2012). It is assumed that each heterogeneous $\mathrm{OH}$ reaction leads to the addition of one oxygen atom, that the fragmentation probability is assumed equivalent to the gas-phase, and that the reactive uptake coefficient is unity. The model additionally requires as input the initial concentration of the parent hydrocarbon, $[\mathrm{HC}]_{0}$, and the (potentially time-dependent) oxidant concentration. In this study, for the low- $\mathrm{NO}_{\mathrm{x}}$ experiments the $[\mathrm{OH}]$ was constant (or nearly constant) throughout, while for the high- $\mathrm{NO}_{\mathrm{x}}$ experiments the $[\mathrm{OH}]$ decayed rapidly. In either case, the model $[\mathrm{OH}]$ was specified so that the observed temporal decay of [HC] was reproduced (see Table 1).

It is not yet clear what the most appropriate functional form is for the fragmentation probability, $P_{\text {frag. }}$. Therefore, two parameterizations are considered here: $P_{\text {frag }}(\mathrm{O}: \mathrm{C})=(\mathrm{O}: \mathrm{C})^{m_{\text {frag }}}$ and $P_{\text {frag }}\left(N_{\mathrm{O}}=c_{\text {frag }} N_{\mathrm{O}}\right)$, where $m_{\text {frag }}$ and $c_{\text {frag }}$ are adjustable parameters, and there is an upper limit of $P_{\text {frag }}=1$. Smaller values of $m_{\text {frag }}$ and larger values of $c_{\text {frag }}$ indicate more extensive fragmentation, respectively. It is assumed that the generated fragments are randomly distributed in terms of where the carbon bond scission occurs.

Best-fit values for $P_{\text {func }}, \Delta \mathrm{LVP}$ and $P_{\text {frag }}$ are determined by simultaneously fitting the time-dependent model predictions to observations of wall-loss corrected organic aerosol mass concentrations $\left(C_{\mathrm{OA}}\right)$ and $\mathrm{O}: \mathrm{C}$ for each system (in this case, $\mathrm{C}_{12}$ compounds reacting with $\mathrm{OH}$ radicals under high- or low- $\mathrm{NO}_{\mathrm{x}}$ conditions). Alternatively, the SOM was fit only to the $C_{\mathrm{OA}}$ observations. The data fitting was performed using the Levenberg-Marquardt algorithm built into the data analysis program Igor. Uncertainties in the measured $C_{\mathrm{OA}}$ were assumed to be the larger of $0.5 \mu \mathrm{g} \mathrm{m}^{-3}$ or $10 \%$. Uncertainties in the O:C were $+/-30 \%$. An upper limit of $\Delta \mathrm{LVP}=2.2$ was applied. The functional group that contributes most to the decrease of vapour pressure per $\mathrm{O}$ atom added is the $-\mathrm{OH}$ group. The EVAPORATION model (Compernolle et al., 2011) predicts that $\triangle$ LVP upon addition of $-\mathrm{OH}$ to primary, secondary and tertiary $\mathrm{C}$ is 2.23 , 
1.70 and 1.16, respectively, whereas the SIMPOL.1 model (Pankow and Asher, 2008) predicts 2.76, 2.10 and 1.49, respectively. Here we take the average between the two vapour pressure models as the upper limit to $\triangle \mathrm{LVP}$. For low- $\mathrm{NO}_{\mathrm{x}}$ experiments, which have a gap in the $C_{\mathrm{OA}}$ data from $\sim 18$ $24 \mathrm{~h}$ of reaction, the data are fit only prior to this gap. As noted above, the reason for this is that the uncertainty in the wall-loss correction across the gap leads to larger uncertainty in the $C_{\mathrm{OA}}$ after the gap.

Variation in the $\mathrm{H}: \mathrm{C}$ atomic ratio with oxidation is characterized within the SOM by specifying the average number of hydrogen atoms lost per oxygen atom added, which is equal to the negative slope in a Van Krevelen diagram (a graph of $\mathrm{H}: \mathrm{C}$ vs. O:C) (Heald et al., 2010). Here, the H-loss-per-Oadded is specified a priori based on the observed Van Krevelen slope, although it should be noted that the specification of this relationship has a negligible influence on the evolution of either the $C_{\mathrm{OA}}$ or O:C.

Condensed phase reactions (besides heterogeneous $\mathrm{OH}$ reactions) are not explicitly accounted for in the SOM. Thus, to the extent that condensed phase reactions (e.g. oligomerization, dehydration, cyclization) alter the observed SOA properties, this will be reflected in the best-fit model parameters.

\section{Results}

\subsection{Low- $\mathrm{NO}_{\mathrm{x}}$ conditions}

The time-evolution of the observed wall-loss corrected SOA mass concentrations $\left(C_{\mathrm{OA}}\right)$ and the particle-phase O:C atomic ratios are shown in Fig. 1, along with the tuned model results obtained using both $P_{\text {frag }}$ parameterizations and after fitting simultaneously to both $C_{\mathrm{OA}}$ and O:C. In general, as oxidation proceeds, the observed $C_{\mathrm{OA}}$ increases until the parent $[\mathrm{HC}]$ decays to around $10 \%$ of its initial value (which occurs around $15-20 \mathrm{~h}$ of oxidation). After this point, the $C_{\mathrm{OA}}$ starts to level off, or even decrease slightly, even though there is still $\mathrm{OH}$ present in the system. The observed SOA $\mathrm{O}: \mathrm{C}$ atomic ratio at early times tends to decrease slightly until the parent $[\mathrm{HC}]$ decays to around $30 \%$ of its initial value (at 5-10 h of oxidation), after which time it begins to slowly increase. Aerosol mass yields for the two ring-containing compounds are larger than for the non-ring containing compounds (Table 1), consistent with previous results from Lim and Ziemann (2009).

The SOM, after fitting, captures the general timedependent behaviour of the observed $C_{\mathrm{OA}}$, with the model $C_{\mathrm{OA}}$ exhibiting a levelling off or slight decrease at long times for many of the simulations (Fig. 1). The exact timedependence of the model $C_{\mathrm{OA}}$ depends somewhat on the assumed fragmentation parameterization and method. In general, the $P_{\text {frag }}\left(N_{\mathrm{O}}\right)$ parameterization tends to show a more pronounced turnover in the $C_{\mathrm{OA}}$ at long times than the $P_{\text {frag }}(\mathrm{O}: \mathrm{C})$ parameterization. The $P_{\text {frag }}\left(N_{\mathrm{O}}\right)$ results appear slightly more consistent with the observations, which is an unexpected result given that the more physically intuitive behavior is that the probability of fragmentation for a given molecule should depend on the relative oxygen abundance (i.e. O:C) rather than the absolute oxygen abundance (i.e. $N_{\mathrm{O}}$ ). However, the uncertainty in the observed $C_{\mathrm{OA}}$ after the data gap limits our ability to definitively make this assessment.

The SOM captures the general shape of the observed O:C time-dependence, with the model O:C typically first decreasing before increasing with time, similar to the experimental results (Fig. 1). Despite the satisfactory shape of the model $\mathrm{O}: \mathrm{C}$ time-dependence, for all of the hydrocarbons considered the absolute value of the model O:C is somewhat greater than the observed O:C, although typically within the experimental uncertainty. Cyclododecane is the notable exception, with a model O:C that is substantially higher than the observed value (although the shape of the calculated and observed time-dependencies are quite similar). The overprediction is, in part, a consequence of setting an upper limit for $\triangle L V P=2.2$ during fitting; allowing for larger values of $\Delta$ LVP can lead to better model/measurement agreement for most compounds (although not for cyclododecane) and can still allow for a good fit to the observed $C_{\mathrm{OA}}$. The $P_{\text {frag }}\left(N_{\mathrm{O}}\right)$ parameterization generally yields somewhat lower absolute $\mathrm{O}: \mathrm{C}$ values compared to $P_{\text {frag }}(\mathrm{O}: \mathrm{C})$. An additional reason for the over-prediction of the model O:C relative to the observations could be that the HR-ToF-AMS underestimates the oxygen derived from hyderoperoxides, with these species instead detected with the-OOH removed (Craven et al., 2012). This would lead to a measured O:C that is somewhat lower than the actual $\mathrm{O}: \mathrm{C}$, with the extent of this disparity potentially dependent upon the hydroperoxide fraction of the oxygenated functional groups.

When the model is fit to both the $C_{\mathrm{OA}}$ and $\mathrm{O}: \mathrm{C}$, the bestfit $\triangle \mathrm{LVP}$ is 2.2 for all compounds, i.e. the imposed upperlimit (Fig. 2 and Table 2). This is not surprising given that the model O:C is particularly sensitive to the $\triangle$ LVP parameter (Cappa and Wilson, 2012). When the model is fit to only the $C_{\mathrm{OA}}$ data, the best-fit values remain high, with $2<\Delta \mathrm{LVP}$ $<2.2$. For all compounds considered, the addition of 1 oxygen atom per reaction was most probable, with some smaller fraction of reactions requiring the addition of 2,3 or 4 oxygen atoms (Fig. 2 and Table 2). The model results indicate that fragmentation is extensive, and the non-ring-containing compounds have larger $c_{\text {frag }}$ and smaller $m_{\text {frag }}$ values compared to the ring-containing compounds, suggesting more extensive fragmentation of the non-ring containing compounds. For all compounds, the $c_{\text {frag }}$ values (for $P_{\text {frag }}\left(N_{\mathrm{O}}\right)$ ) were $\geq 0.33$, which indicates that any molecule already containing 3 or more oxygen atoms will exclusively fragment upon reaction. Note that this does not preclude formation of species with $>3$ oxygen atoms because some reactions add more than 1 oxygen atom and because fragmentation also leads to oxygen addition. It does, however, limit the rate and overall extent 

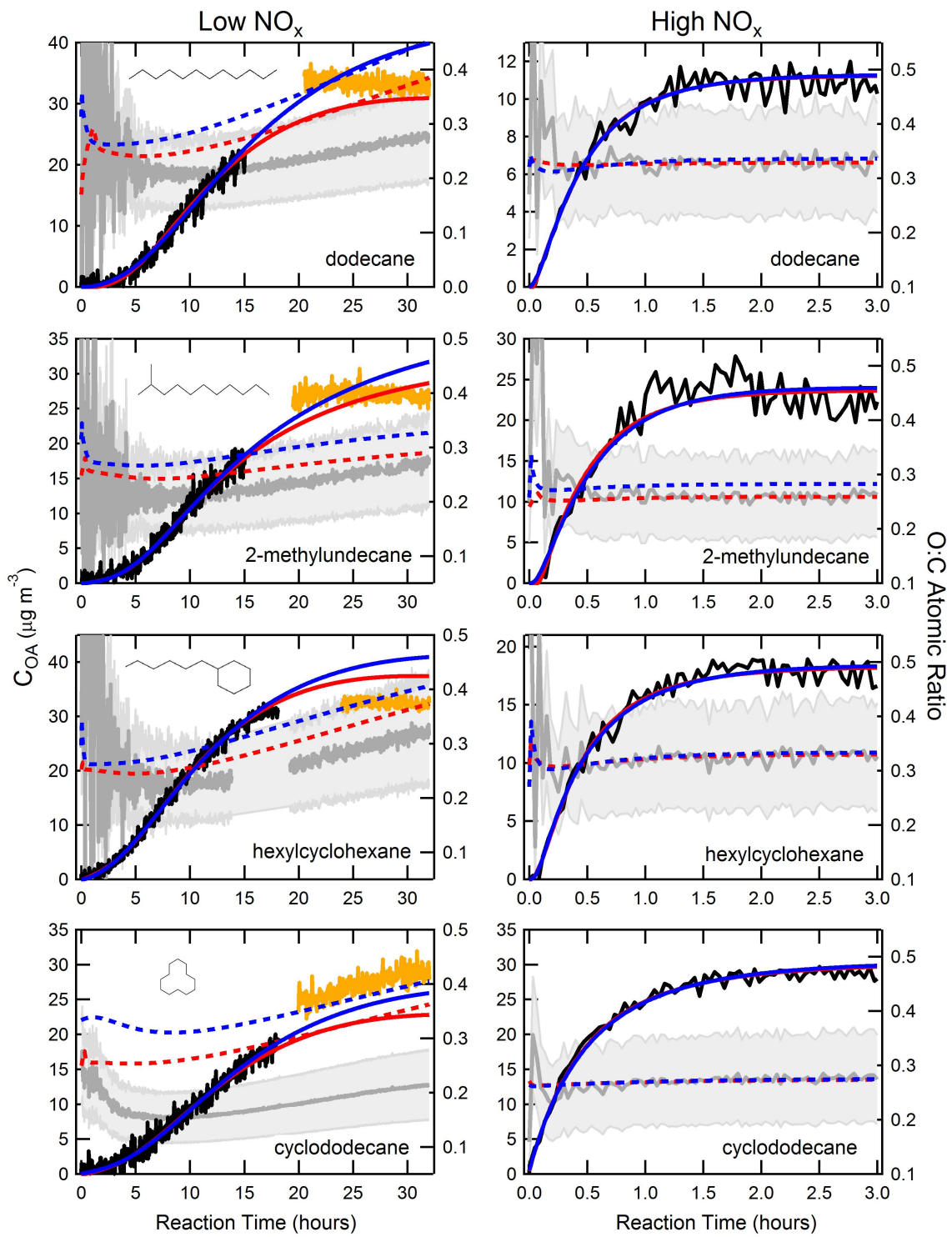

$$
\text { Observations: } \begin{array}{rrr}
-C_{\mathrm{OA}} & \text { Model: } & P_{\text {frag }}=c_{\text {frag }} \times N_{\mathrm{O}}:-C_{\mathrm{OA}} ;-\cdots \mathrm{O}: \mathrm{C} \\
-\mathrm{O}: \mathrm{C} & P_{\text {frag }}=(\mathrm{O}: \mathrm{C})^{m_{\text {frag }}}:-C_{\mathrm{OA}} ; \cdots \mathrm{O}: \mathrm{C}
\end{array}
$$

Fig. 1. Evolution of the SOA mass concentration, $C_{\mathrm{OA}}$, (black lines, left axes) and O:C atomic ratio (gray lines, right axes) for low-NO (left panels) and high- $\mathrm{NO}_{\mathrm{x}}$ (right panels) for dodecane, 2-methylundecane, hexylcyclohexane and cyclododecane (top-to-bottom). The light gray bands on the O:C indicate the estimated uncertainty range $( \pm 30 \%)$. The model results using $P_{\text {frag }}\left(N_{\mathrm{O}}\right)$ and $P_{\text {frag }}(\mathrm{O}: \mathrm{C})$ are shown as red and blue lines, respectively. Solid lines are model fits for $C_{\mathrm{OA}}$ and dashed lines for O:C. The model has been fit simultaneously to the $C_{\mathrm{OA}}$ and O:C data for $t<15 \mathrm{~h}$ (low- $\mathrm{NO}_{\mathrm{x}}$, black lines) or $t<3 \mathrm{~h}$ (high- $\mathrm{NO}_{\mathrm{x}}$ ). For the low- $\mathrm{NO}_{\mathrm{x}}$ conditions, the orange lines correspond to data collected after a pause in sampling (indicated by a gap in the $C_{\mathrm{OA}}$ time series).

to which such highly oxygenated species can form. Similar conclusions are reached if the $P_{\text {frag }}(\mathrm{O}: \mathrm{C})$ parameterization is instead considered, although the exact details are changed somewhat due to the different functional form of the parameterization.

The observed co-variation of $\mathrm{H}: \mathrm{C}$ with $\mathrm{O}: \mathrm{C}$, shown as a Van Krevelen diagram, indicates that the number of $\mathrm{H}$ atoms lost per $\mathrm{O}$ atom added, or the negative slope on the graph, ranges from 1.45 to 2.2 (Fig. 3); this parameter is specified within the SOM so as to match the model to the observations. The model aerosol exhibits a continuous evolution of the $\mathrm{H}: \mathrm{C}$ and $\mathrm{O}: \mathrm{C}$ throughout the reaction, consistent with the observations, which is indicated by the wide range of values that fall along a line with a constant slope (Fig. 3).

The distribution of molecules in $N_{\mathrm{C}} / N_{\mathrm{O}}$ space at the end of the dodecane $+\mathrm{OH}$ reaction is shown for both $P_{\text {frag }}$ 
Table 2. Statistical oxidation model best-fit parameters when fit to both $\mathrm{C}_{\mathrm{OA}}$ and O:C.

\begin{tabular}{|c|c|c|c|}
\hline Alkane & $\Delta \mathrm{LVP}$ & $c_{\text {frag }}$ or $m_{\text {frag }}$ & $\begin{array}{l}\text { Oxygen Addition } \\
\text { Probabilities }^{\mathrm{a}}\end{array}$ \\
\hline \multicolumn{4}{|c|}{ Low-NO ${ }_{\mathrm{x}} ; P_{\text {frag }}=c_{\text {frag }} N_{\mathrm{O}}$} \\
\hline dodecane & $2.20^{\mathrm{b}}$ & 0.423 & {$[0.57,0.12,0.00,0.31]$} \\
\hline 2-methylundecane & $2.20^{\mathrm{b}}$ & 0.455 & {$[0.79,0.00,0.10,0.11]$} \\
\hline hexylcyclohexane & $2.20^{\mathrm{b}}$ & 0.333 & {$[0.80,0.05,0.12,0.03]$} \\
\hline cyclododecane & $2.20^{\mathrm{b}}$ & 0.333 & {$[0.86,0.02,0.12,0.0]$} \\
\hline \multicolumn{4}{|c|}{ Low-NO ${ }_{\mathrm{x}} ; P_{\text {frag }}=(\mathrm{O}: \mathrm{C})^{m \text { frag }}$} \\
\hline dodecane & $2.20^{\mathrm{b}}$ & 0.077 & {$[0.79,0.17,0.03,0.0]$} \\
\hline 2-methylundecane & $2.20^{\mathrm{b}}$ & 0.110 & {$[0.96,0.0,0.04,0.0]$} \\
\hline hexylcyclohexane & $2.20^{\mathrm{b}}$ & 0.214 & {$[0.75,0.17,0.08,0.0]$} \\
\hline cyclododecane & $2.20^{\mathrm{b}}$ & 0.250 & {$[0.88,0.0,0.0,0.11]$} \\
\hline \multicolumn{4}{|c|}{ High- $\mathrm{NO}_{\mathrm{x}} ; P_{\text {frag }}=c_{\text {frag }} N_{\mathrm{O}}$} \\
\hline dodecane & 1.46 & 0.279 & {$[0.31,0.41,0.07,0.19]$} \\
\hline 2-methylundecane & 1.68 & 0.397 & {$[0.24,0.50,0.27,0.0]$} \\
\hline hexylcyclohexane & 1.54 & 0.233 & {$[0.0,0.50,0.43,0.06]$} \\
\hline cyclododecane & 2.01 & 0.279 & {$[0.0,0.0,0.73,0.26]$} \\
\hline \multicolumn{4}{|c|}{ High- $\mathrm{NO}_{\mathrm{X}} ; P_{\text {frag }}=(\mathrm{O}: \mathrm{C})^{m \text { frag }}$} \\
\hline dodecane & 1.69 & 0.105 & {$[0.26,0.38,0.31,0.05]$} \\
\hline 2-methylundecane & 1.80 & 0.113 & {$[0.30,0.57,0.13,0.0]$} \\
\hline hexylcyclohexane & 1.67 & 0.191 & {$[0.18,0.23,0.59,0.0]$} \\
\hline cyclododecane & 2.06 & 0.251 & {$[0.0,0.0,0.88,0.12]$} \\
\hline
\end{tabular}

a The relative probabilities of adding 1, 2, 3 or 4 oxygen atoms per reaction.

b Constrained as an upper limit.

parameterizations (Fig. 4a,b). Overall, the OA is dominated by compounds that have $N_{\mathrm{C}}=12$ (Fig. 4e), although there are interestingly contributions from compounds with as few as 2 carbons at the $0.1 \%$ level. Although the two $P_{\text {frag }}$ parameterizations give generally similar results with respect to the temporal variation in the $C_{\mathrm{OA}}$ and $\mathrm{O}: \mathrm{C}$, the distribution of molecules that make up the OA differ. The $P_{\text {frag }}(\mathrm{O}: \mathrm{C})$ parameterization allows for a fragmentation probability that asymptotically approaches 1 (at $\mathrm{O}: \mathrm{C}=1$ ), and thus it is possible to produce molecules with $N_{\mathrm{C}}=12$ and with a relatively large number of oxygen atoms, although the contribution of species with $N_{\mathrm{O}}>3$ to the total OA mass is small. For the $P_{\text {frag }}\left(N_{\mathrm{O}}\right)$ parameterization the probability of fragmentation linearly varies with $N_{\mathrm{O}}$ and, given $c_{\text {frag }}=0.42$ coupled with a $P_{\text {func }}$ array dominated by 1 oxygen per reaction, there is similarly not substantial production of $N_{\mathrm{C}}=12$ species with $N_{\mathrm{O}}>3$.

\subsection{High-NO $\mathrm{N}_{\mathrm{x}}$ conditions}

The observed variations in wall-loss corrected $C_{\mathrm{OA}}$ and $\mathrm{O}: \mathrm{C}$ with reaction time for high- $\mathrm{NO}_{\mathrm{x}}$ conditions for each of the alkanes considered are shown in Fig. 1. It is important to note that the $\mathrm{OH}$ concentration during these experiments was time dependent and decayed rapidly from $>10^{7}$ molecules $\mathrm{cm}^{-3}$ to zero (by around $3 \mathrm{~h}$ ). This is in contrast to the low- $\mathrm{NO}_{\mathrm{x}}$ experiments, where the $\mathrm{OH}$ concentration was constant at around $3 \times 10^{6}$ molecules $\mathrm{cm}^{-3}$. The time-dependence of the $[\mathrm{OH}]$ was accounted for in the SOM fit to the observations. The observed $C_{\mathrm{OA}}$ in each experiment rapidly increased before reaching a plateau by around $2-3 \mathrm{~h}$. Unlike the low- $\mathrm{NO}_{\mathrm{x}}$ experiments, this plateau behaviour results primarily from the loss of $\mathrm{OH}$ radicals and the cessation of photochemical reactions and not from an evolution in the distribution of gas-phase photooxidation products. The observed SOA $\mathrm{O}: \mathrm{C}$ were essentially constant with time. Aerosol mass yields were larger for the ring-containing compounds (Table 1).

The SOM reproduces the observed time-dependent behaviour of the $C_{\mathrm{OA}}$ and $\mathrm{O}: \mathrm{C}$, both in terms of shape and absolute magnitude. Note that the close match between the observed and predicted $\mathrm{O}: \mathrm{C}$ is different than for the low- $\mathrm{NO}_{\mathrm{x}}$ conditions, where O:C was over-predicted. Fitting to either $C_{\mathrm{OA}}$ and O:C simultaneously or only to $C_{\mathrm{OA}}$ gave generally similar results. The best-fit $\triangle \mathrm{LVP}$ values ranged from 1.46 to 2.06 (Fig. 2 and Table 2) and are overall substantially lower compared to the low- $\mathrm{NO}_{\mathrm{x}}$ systems, with the exception of cyclododecane. Under high- $\mathrm{NO}_{\mathrm{x}}$ conditions the optimal fit of the SOM indicates that the majority of reactions 

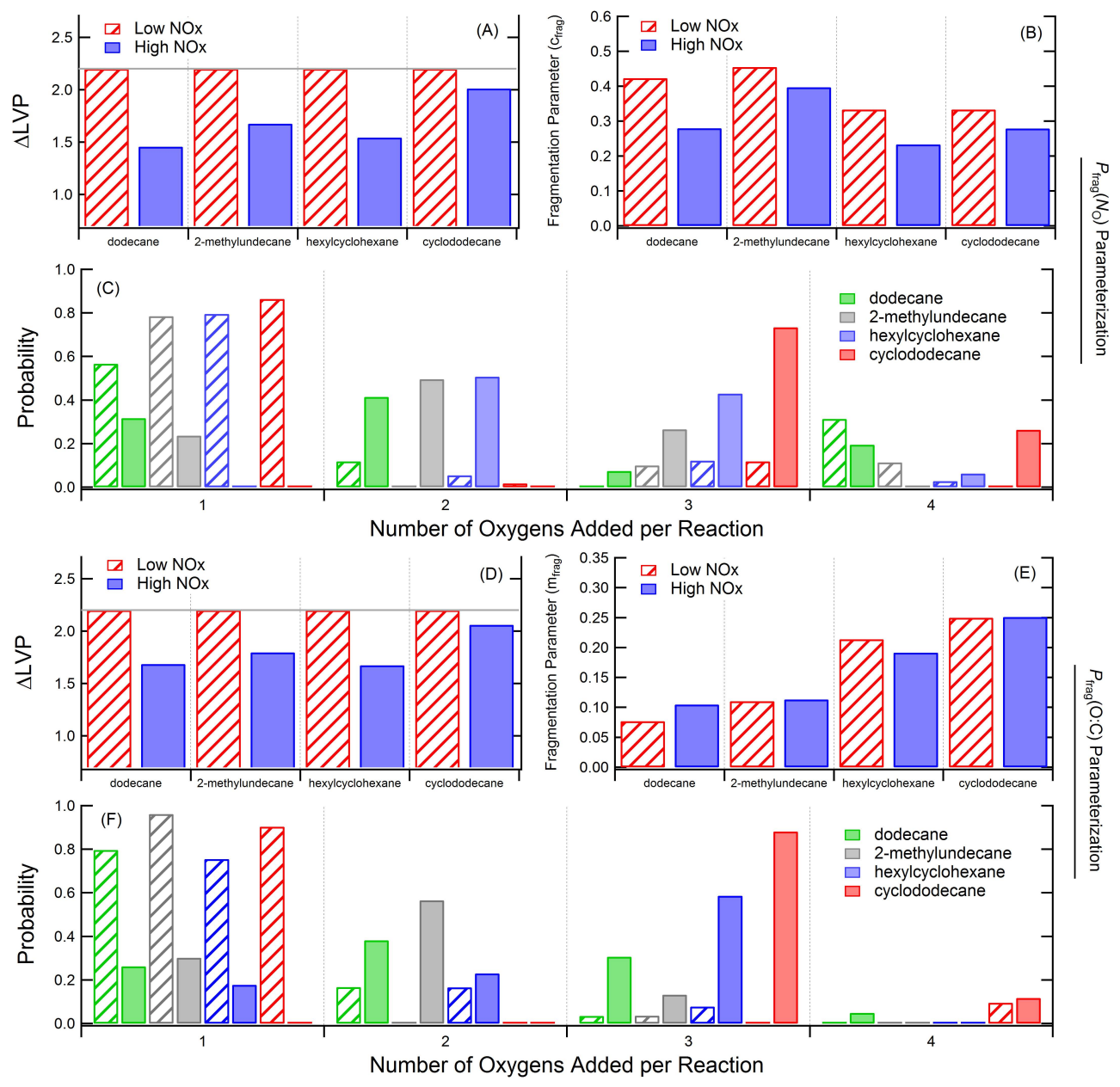

Fig. 2. Best-fit SOM parameters for dodecane, 2-methylundecane, hexylcyclohexane, and cyclodecane under low- $\mathrm{NO}_{\mathrm{x}}$ (hashed) and high$\mathrm{NO}_{\mathrm{x}}$ (solid) conditions for different parameterizations for fragmentation: (A-C) used $P_{\text {frag }}\left(N_{\mathrm{O}}\right)$ while (D-F) used $P_{\text {frag }}(\mathrm{O}: \mathrm{C})$. Results are shown for $\triangle \mathrm{LVP}$ ( $\mathbf{A}$ and $\mathbf{D})$ ), the fragmentation parameter $(\mathbf{B}$ and $\mathbf{E}$ ) and the oxygen addition array $(\mathbf{C}$ and $\mathbf{F})$. The model was fit simultaneously to the observed $C_{\mathrm{OA}}$ and $\mathrm{O}: \mathrm{C}$. The two fragmentation parameterizations give generally similar results. Note that for the fragmentation parameter, larger values of $c_{\text {frag }}$ correspond to greater fragmentation while smaller values of $m_{\text {frag }}$ correspond to greater fragmentation. The grey line in (A) and (D) indicates the upper-limit constraint on $\triangle$ LVP.

added 2 to 4 oxygen atoms per reaction, with the exact probability distribution varying for each alkane considered and some probability of adding 1 oxygen per reaction (with the exception of cyclododecane). This is in distinct contrast to the low- $\mathrm{NO}_{\mathrm{x}}$ systems, where predominately only 1 oxygen is predicted to be added per reaction. The $P_{\text {func }}$ distributions are generally similar between the two fragmentation parameterizations. In general, the non-ring-containing compounds require larger $c_{\text {frag }}$ (or smaller $m_{\text {frag }}$ ) than the ring-containing compounds, indicating more extensive fragmentation. Additionally, the best-fit $c_{\text {frag }}$ values are generally larger (and the $m_{\text {frag }}$ smaller) under high- $\mathrm{NO}_{\mathrm{x}}$ conditions than under low$\mathrm{NO}_{\mathrm{x}}$ conditions for a given compound, although the extent to which the values differ depends on the specific alkane and whether $c_{\text {frag }}$ or $m_{\text {frag }}$ is considered; in some cases the differences are slight (Fig. 2 and Table 2).
The observed co-variation of $\mathrm{H}: \mathrm{C}$ with $\mathrm{O}: \mathrm{C}$ indicates that the number of $\mathrm{H}$ atoms lost per $\mathrm{O}$ atom added ranges from 1.25 to 1.83 , which is slightly less than for low- $\mathrm{NO}_{\mathrm{x}}$ conditions (Fig. 3). The SOM captures the observed behaviour (after specifying the H-per-O relationship), namely that the $\mathrm{H}: \mathrm{C}$ and $\mathrm{O}: \mathrm{C}$ are both nearly constant throughout the reaction, unlike the low- $\mathrm{NO}_{\mathrm{x}}$ systems (Fig. 3).

The distribution of molecules in $N_{\mathrm{C}} / N_{\mathrm{O}}$ space at the end of the reaction is shown for dodecane (Fig. 4c,d). As in the low- $\mathrm{NO}_{\mathrm{x}}$ systems, the overall SOA composition is dominated by compounds with $N_{\mathrm{C}}=12$ (Fig. 4e), although the fractional contribution of compounds with $N_{\mathrm{C}}<12$ is less than in the low- $\mathrm{NO}_{\mathrm{x}}$ experiments. This is likely the result of a greater number of oxygen atoms being added per reaction for the high- vs. low- $\mathrm{NO}_{\mathrm{x}}$ case. This predicts that compounds with $N_{\mathrm{C}}=12$ more rapidly add oxygen, leading to a volatility 

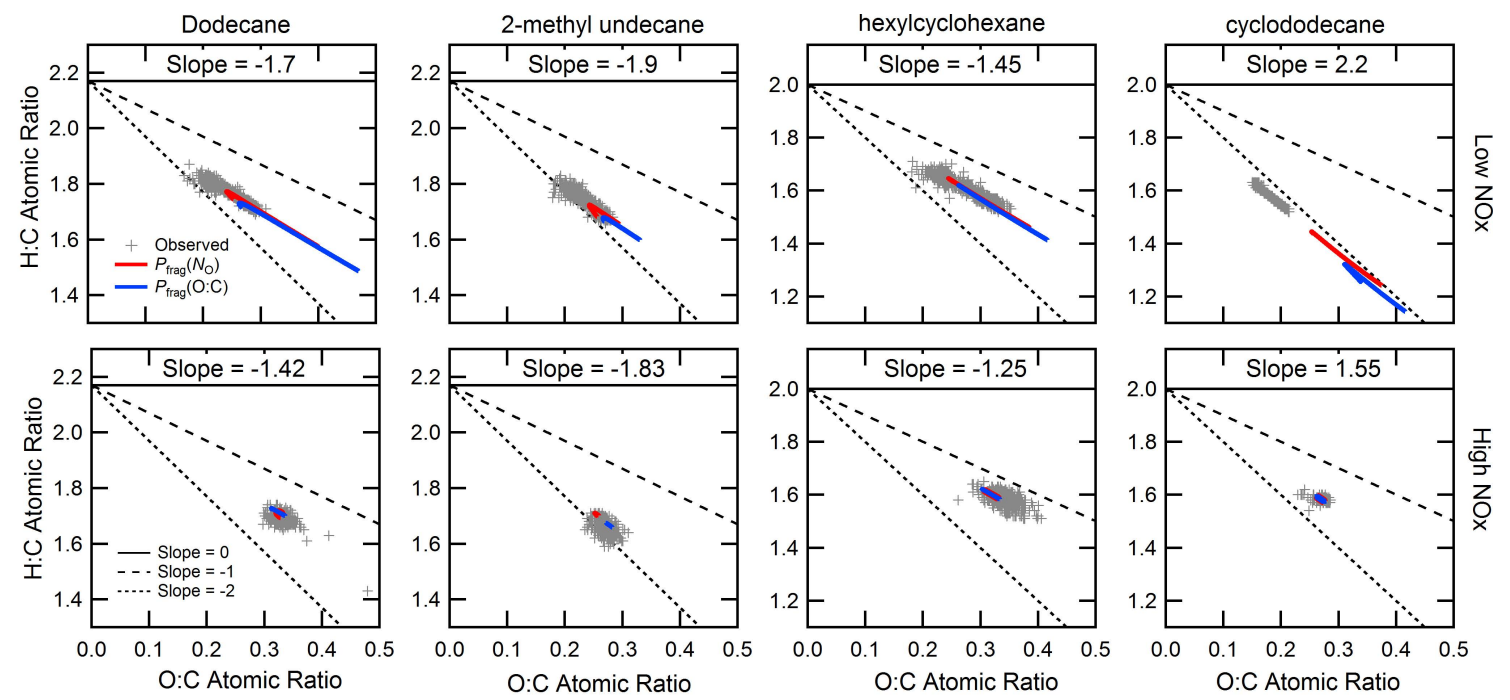

Fig. 3. Van Krevelen diagrams (H:C vs. O:C) for the observed SOA (gray points) and the model SOA using the $P_{\text {frag }}\left(N_{\mathrm{O}}\right)($ red lines) and $P_{\text {frag }}(\mathrm{O}: \mathrm{C})$ (blue lines) fragmentation parameterizations. The top row shows results for low- $\mathrm{NO}_{\mathrm{x}}$ conditions and the bottom row for high-NO conditions. The Van Krevelen slopes (defined according to the parent hydrocarbon y-intercept) are given in each panel.

sufficiently low that condensation is efficient even though the $\Delta$ LVP tends to be smaller for the high- $\mathrm{NO}_{\mathrm{x}}$ mechanisms.

\section{Discussion}

The observations indicate that aerosol mass yields, defined as $C_{\mathrm{OA}} / \Delta \mathrm{HC}$ (where $\Delta \mathrm{HC}$ is the amount of precursor reacted), are larger for the ring-containing compounds than for the non-ring-containing compounds for both high- and low$\mathrm{NO}_{\mathrm{x}}$ conditions (Table 1). For equivalent amounts of aerosol formed (specifically, $10 \mu \mathrm{g} \mathrm{m}^{-3}$ ), the mass yields for each species under high- and low- $\mathrm{NO}_{\mathrm{x}}$ conditions are reasonably similar, with the exception of cyclododecane, for which the high- $\mathrm{NO}_{\mathrm{x}}$ yield is greater (Table 1). Low- $\mathrm{NO}_{\mathrm{x}}$ conditions typically have greater $\mathrm{H}$-loss per $\mathrm{O}$-added (i.e. more negative Van Krevelen slopes) than high- $\mathrm{NO}_{\mathrm{x}}$ conditions and also exhibit a more continuous evolution through the Van Krevelen space as the reactions proceed. Considering the model results, the SOM indicates that the decrease in volatility per oxygen added is substantially larger for low- $\mathrm{NO}_{\mathrm{x}}$ vs. high$\mathrm{NO}_{\mathrm{x}}$ conditions. The magnitude of the fragmentation parameter, $c_{\text {frag }}$, is generally larger (and $m_{\text {frag }}$ smaller) for low- vs. high- $\mathrm{NO}_{\mathrm{x}}$. Under high- $\mathrm{NO}_{\mathrm{x}}$ conditions a greater number and broader distribution of oxygen atoms are added, on average, per reaction. Low- $\mathrm{NO}_{\mathrm{x}}$ conditions lead to a slightly broader distribution of compounds with $N_{\mathrm{C}}<12$ in the particle phase compared to high- $\mathrm{NO}_{\mathrm{x}}$ conditions.

To facilitate further comparison between the low- $\mathrm{NO}_{\mathrm{x}}$ and high- $\mathrm{NO}_{\mathrm{x}}$ experiments, which were conducted using different $[\mathrm{OH}]$ temporal profiles and different $[\mathrm{HC}]_{0}$, timedependent SOA growth simulations were run under the same reaction conditions using the best-fit parameters determined above (Fig. 5). Specific reaction conditions and model inputs were: $[\mathrm{OH}]=2.5 \times 10^{6}$ molecules $\mathrm{cm}^{-3},[\mathrm{HC}]_{0}=33.5 \mathrm{ppb}$, the $P_{\text {frag }}\left(N_{\mathrm{O}}\right)$ parameterization was used and the model was run for $32 \mathrm{~h}$ of oxidation. For all except 2-methylundecane, the $C_{\mathrm{OA}}$ formed after a given reaction time is initially somewhat greater for the high- $\mathrm{NO}_{\mathrm{x}}$ conditions, but with an eventual cross-over to where the $C_{\mathrm{OA}}$ becomes larger for the low$\mathrm{NO}_{\mathrm{x}}$ conditions, often substantially so, at long times. For 2methylundecane the yield under low- $\mathrm{NO}_{\mathrm{x}}$ conditions is always greater than under high- $\mathrm{NO}_{\mathrm{x}}$ conditions, with the difference growing with time.

For high- $\mathrm{NO}_{\mathrm{x}}$ conditions there tends to be a more pronounced turnover in the $C_{\mathrm{OA}}$ with time and with the turnover occurring at shorter times compared to low- $\mathrm{NO}_{\mathrm{x}}$ conditions. The overall time-dependent evolution of the gas + particle system reflects the combined influence of all of the parameters ( $P_{\text {frag }}$ and $P_{\text {func }}$ and $\left.\Delta \mathrm{LVP}\right)$. Thus, the observed $\mathrm{NO}_{\mathrm{x}}-$ dependence on the time-dependent aerosol yields can be understood through the influence of $\mathrm{NO}_{\mathrm{x}}$ on both the probabilities of fragmentation vs. functionalization reactions and on the nature of the functional groups formed, specifically the decrease in volatility that occurs upon functional group addition.

There are no clear, systematic differences in the evolution of the O:C with oxidation between the low- and high$\mathrm{NO}_{\mathrm{x}}$ cases, although $\mathrm{O}: \mathrm{C}$ tends to be slightly higher for high- $\mathrm{NO}_{\mathrm{x}}$. In general, for low- $\mathrm{NO}_{\mathrm{x}}$ the O:C first decreases then increases, consistent with the experiments (which were conducted under similar conditions as these simulations). For high- $\mathrm{NO}_{\mathrm{x}}$, both 2-methylundecane and hexylcyclohexane exhibit a noticeable increase in the $\mathrm{O}: \mathrm{C}$ with oxidation, similar to the low- $\mathrm{NO}_{\mathrm{x}}$ cases, whereas dodecane and 

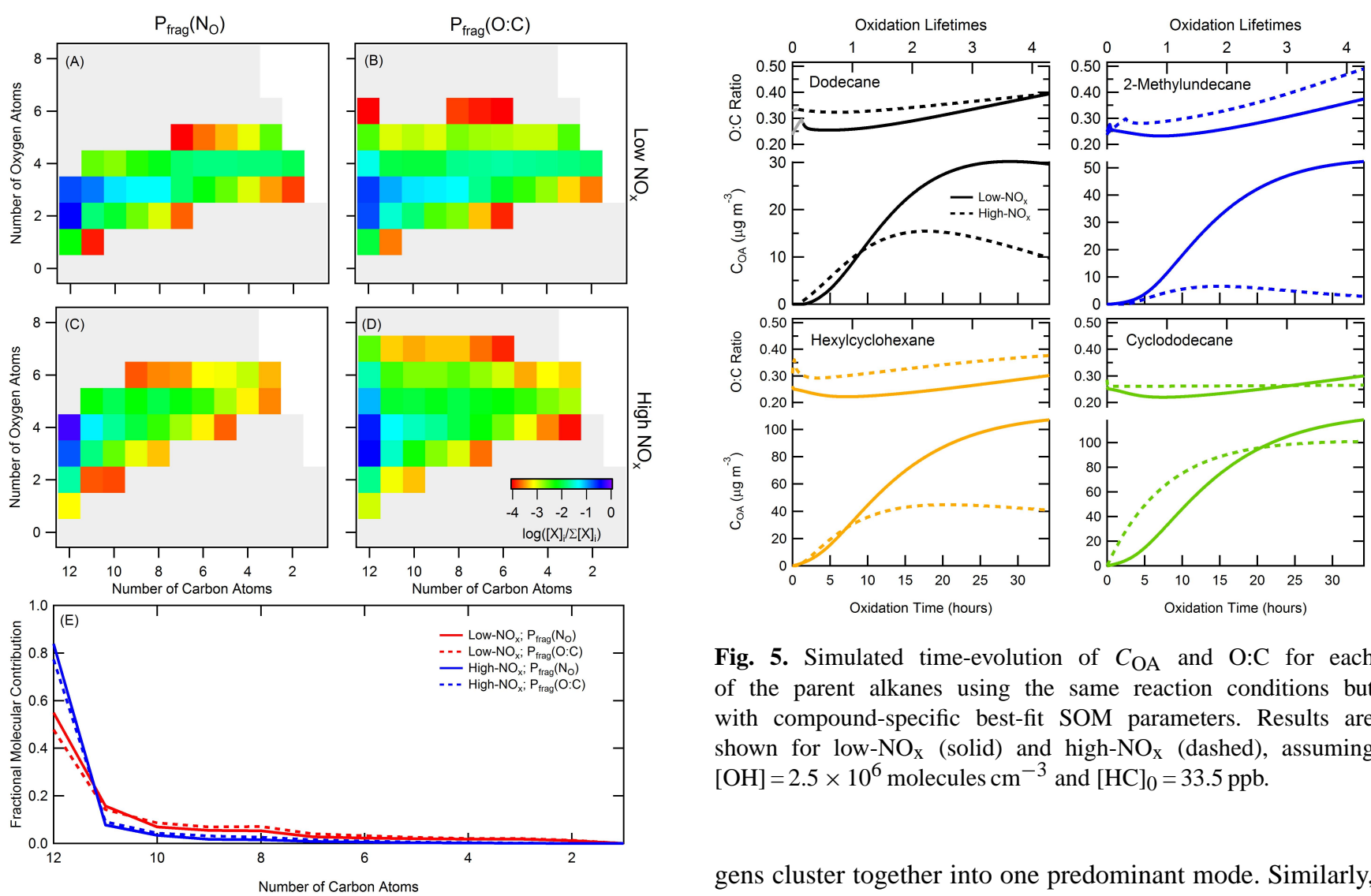

Fig. 5. Simulated time-evolution of $C_{\mathrm{OA}}$ and $\mathrm{O}: \mathrm{C}$ for each of the parent alkanes using the same reaction conditions but with compound-specific best-fit SOM parameters. Results are shown for low- $\mathrm{NO}_{\mathrm{x}}$ (solid) and high- $\mathrm{NO}_{\mathrm{x}}$ (dashed), assuming $[\mathrm{OH}]=2.5 \times 10^{6}$ molecules $\mathrm{cm}^{-3}$ and $[\mathrm{HC}]_{0}=33.5 \mathrm{ppb}$.

Fig. 4. Distribution of molecules comprising the model dodecane SOA at the end of the experiment for low- $\mathrm{NO}_{\mathrm{x}}(\mathbf{A}, \mathbf{B})$ and high$\mathrm{NO}_{\mathrm{X}}(\mathbf{C}, \mathbf{D})$ for the $P_{\text {frag }}\left(N_{\mathrm{O}}\right)(\mathbf{A}, \mathbf{C})$ and $P_{\text {frag }}(\mathrm{O}: \mathrm{C})(\mathbf{B}, \mathbf{D})$ parameterizations. The colors correspond to the log of the fractional molecular abundance, i.e. $\log \left([\mathrm{X}]_{j} / \Sigma[\mathrm{X}]_{j}\right)$, with a lower-limit of $-4(=0.01 \%)$. (E) The distributions, binned by $N_{\mathrm{C}}$, for low- $\mathrm{NO}_{\mathrm{x}}$ (red) and high- $\mathrm{NO}_{\mathrm{x}}$ (blue).

cyclododecane exhibit comparably small variations in O:C with oxidation.

\subsection{Time-evolution of individual SOA species}

The SOM can be used to follow the time-evolution of the individual species (i.e. $N_{\mathrm{C}} / N_{\mathrm{O}}$ pairs) that comprise the model SOA. Tracking of each SOM species can help to understand which species contribute most to the SOA mass at any given time during the experiment, and thus how the composition is evolving. An example of such a time-trace is shown for the low- $\mathrm{NO}_{\mathrm{x}}$ dodecane system using the $P_{\text {frag }}\left(N_{\mathrm{O}}\right)$ parameterization, where the individual species have been normalized to their maximum concentration (Fig. 6). It can be seen that there is some clustering of different species with respect to their specific time-evolution, and species that exhibit similar time-dependent behaviour have been colored similarly. The $N_{\mathrm{C}}=12$ species with 1 and 2 oxygen atoms have unique time-profiles while the $N_{\mathrm{C}}=8$ to 11 species with 1 or 2 oxy-

gens cluster together into one predominant mode. Similarly, there is a clustering of species with $N_{\mathrm{C}}=6-7$ and $N_{\mathrm{O}}=2-3$, and of species with $N_{\mathrm{C}}=8-12$ with $N_{\mathrm{O}}=3$. Finally, species with $N_{\mathrm{O}} \geq 4$ cluster together nearly independent of $N_{\mathrm{C}}$. This type of clustering behaviour is consistent with the identification of unique "factors" associated with the formation and ageing of low- $\mathrm{NO}_{\mathrm{x}}$ dodecane SOA (Craven et al., 2012). In general, the concentrations of individual particle-phase species with greater numbers of oxygen atoms and smaller carbon atom numbers peak later in time, consistent with their formation occurring only after many generations of oxidation. (Note that the assumption of random fragmentation and the use of a single SOM "grid" preclude direct, quantitative connections between $N_{\mathrm{C}}, N_{\mathrm{O}}$ and generation number to be made.) The clustering of particular species in terms of their particle-phase concentrations is related to the combined influence of gas-phase formation rates and the volatility of each species.

It is also important to consider the actual time-dependent contributions from each species to the total SOA mass, as the above discussion (which uses normalized traces) might place undue focus on species that contribute negligibly to the SOA mass. Figure 7a shows the actual time-evolution of the particle phase mass concentration for each SOM species, and Fig. 7b-d show snapshots of the concentrations of each species after $5 \mathrm{~h}, 15 \mathrm{~h}$ and $25 \mathrm{~h}$ of reaction, normalized to the total particle mass at that time. It is evident that at early times the SOA is dominated by the $N_{\mathrm{C}}=12, N_{\mathrm{O}}=2$ species and the cluster of $N_{\mathrm{C}}=8-12, N_{\mathrm{O}}=3$ species. As the 

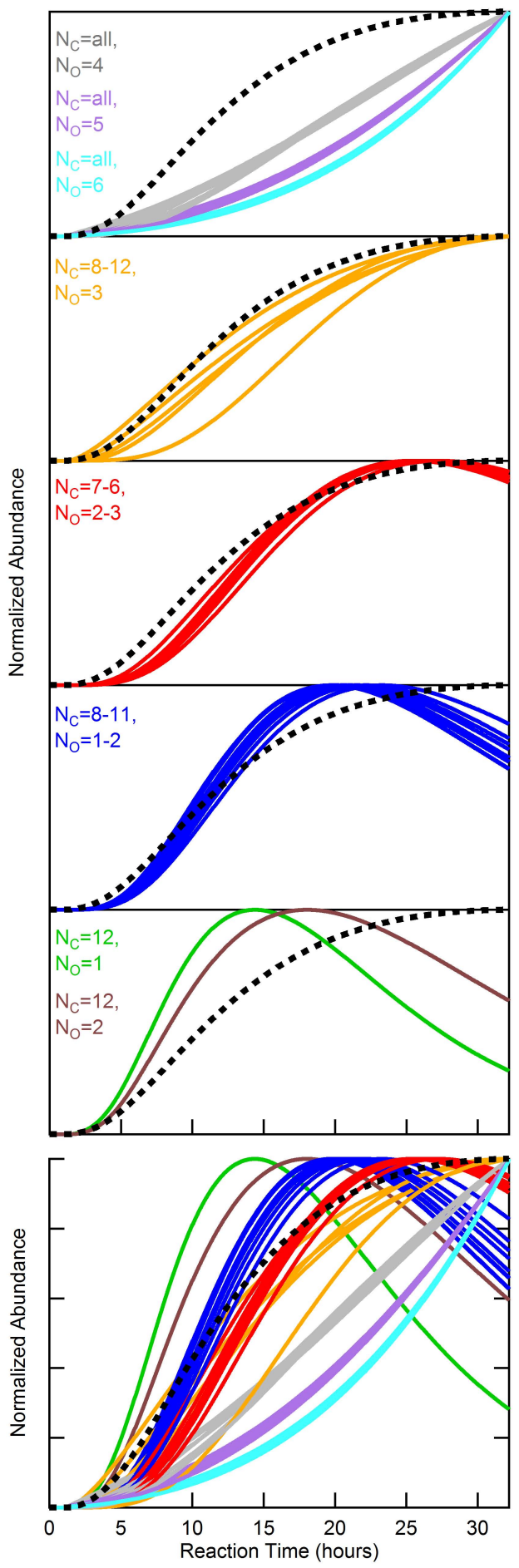

Fig. 6. Simulated time-evolution of each SOM species (i.e. $N_{\mathrm{C}} / N_{\mathrm{O}}$ pair) during the low- $\mathrm{NO}_{\mathrm{x}}$ photooxidation of dodecane. Species that exhibit a similar temporal dependence have been grouped into "clusters" and are shown in individual panels with the same color; the $N_{\mathrm{C}}$ and $N_{\mathrm{O}}$ of the species that belong to each "cluster" for each panel are indicated as labels. Each species profile has been normalized to its maximum concentration. For reference, the dashed black trace in each panel shows the time-evolution of the normalized total SOA mass. The bottom panel shows all traces together so that the time-evolution of the various clusters can be compared.
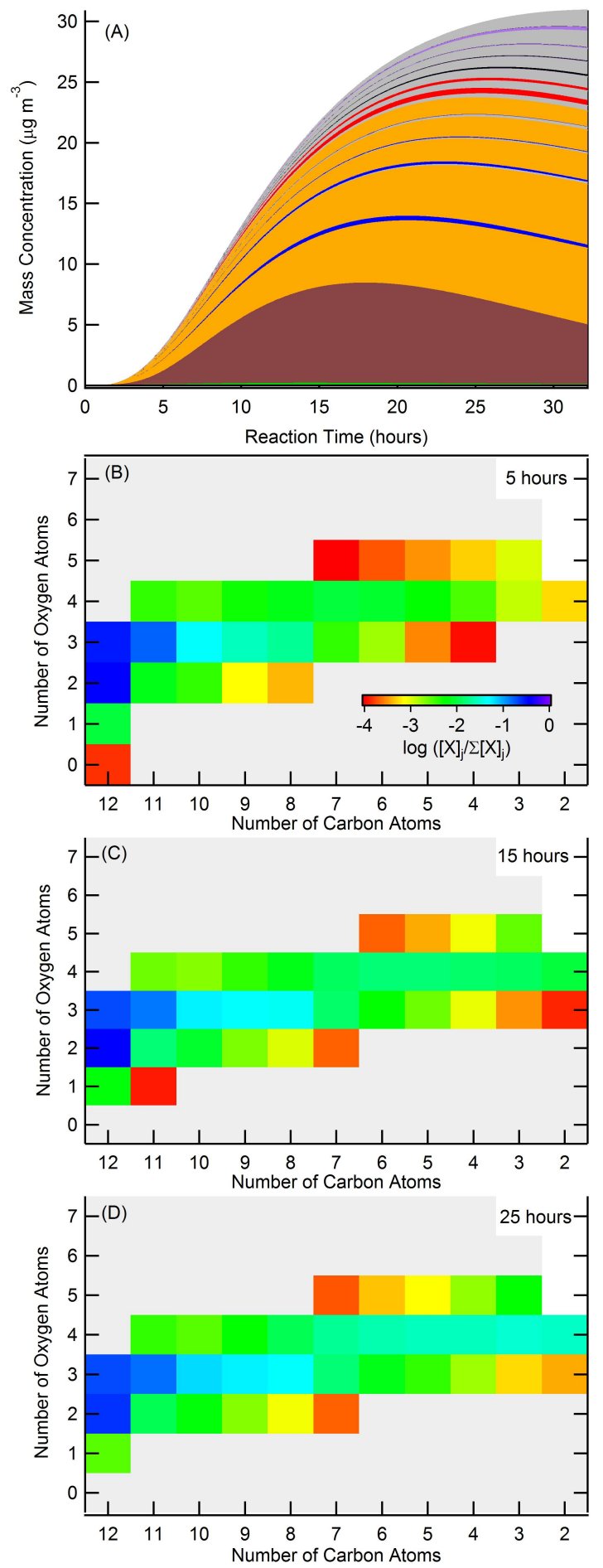

Fig. 7. (A) Simulated mass concentrations of each SOM species, with each species stacked on the previous. The colors correspond to those in Fig. 6 and indicate species of a particular "cluster". (B), (C) and (D) show snapshots at 5, 15 and 25 hours of reaction, respectively, of the normalized mass concentration of all SOM species on an oxygen/carbon grid, with concentration indicated by the color of each cell in the grid (see legend). For each snapshot, the mass concentration of each species is normalized by the total SOA mass concentration as in Fig. 4; species with a normalized abundance $<10^{-4}$ are shown as gray and species with $\mathrm{O}: \mathrm{C}>2$ are shown as white. 
reaction progresses, the cluster of $N_{\mathrm{O}}=4$ species begins to contribute significantly while the abundance of the $N_{\mathrm{C}}=12$, $N_{\mathrm{O}}=2$ species decreases as it is converted into more oxidized species. This illustrates the dynamic nature of the SOA composition as it forms and ages.

\subsection{Relationship of $\triangle L V P$ and oxygen addition}

In principle, the addition of different functional groups corresponds to different values for $\triangle \mathrm{LVP}$ in the SOM. For example, the SIMPOL model of Pankow and Asher (2008) suggests the following: $\triangle \mathrm{LVP}($ alcohol $) \sim 2.23 ; \Delta \mathrm{LVP}$ (ketone) $\sim 0.94 ; \quad \Delta \operatorname{LVP}$ (aldehyde) $\sim 1.35 ; \quad \Delta \operatorname{LVP}($ nitrate) $\sim 0.74$; $\triangle \mathrm{LVP}($ hydroperoxide) $\sim 1.24$. (Recall that $\triangle \mathrm{LVP}$ is defined on a per-oxygen basis.)

Under low- $\mathrm{NO}_{\mathrm{x}}$ reaction conditions, likely products from gas-phase pathways are hydroperoxides, carbonyl hydroperoxides, hydroxyl hydroperoxides, carboxylic acids, hydroxylcarboxylic acids, hydroxyperacids and hydroxyl carbonyls (Yee et al., 2012). For the low- $\mathrm{NO}_{\mathrm{x}}$ systems the best-fit SOM $\Delta$ LVP values are all $>2$, which would suggest the addition of predominately hydroxyl $(-\mathrm{OH})$ functional groups. However, addition only of alcohols seems unlikely, both from a mechanistic perspective (Yee et al., 2012) and from consideration of the observed H-loss per O-added (or Van Krevelen slope). Strict alcohol addition would correspond to a Van Krevelen slope of 0, which can be compared with the addition of a ketone or aldehyde (slope $=-2$ ) or hydroperoxide (slope $=0$ ). The observed low- $\mathrm{NO}_{\mathrm{x}}$ Van Krevelen slopes ranged from -1.45 to -2.2 . Such values are more suggestive of substantial ketone or aldehyde addition, as opposed to addition of alcohols, ketones and hydroperoxides as suggested by Yee et al. (2012). Thus, there appears to be some inconsistency between the model $\triangle$ LVP values, the observed Van Krevelen slopes and the expected products.

One potential reconciliation between these differing indications of functional group addition is the presence of condensed phase reactions. The above functional group/ $\Delta \mathrm{LVP}$ relationships do not account for condensed phase reactions that can alter the nature of the functional groups comprising the SOA (and thus the H:C and O:C relationship) and the apparent volatility of the condensed-phase compounds. Importantly, certain condensed phase reactions involve a change in the Van Krevelen slope while others preserve the slope. Dehydration reactions involve loss of water molecules and lead to a change in the observed $\mathrm{H}: \mathrm{C}$ vs. O:C slope, moving it towards steeper values. For example, ester formation, typically from the reaction of a carboxylic acid and alcohol, involves loss of a water molecule:

$\mathrm{R}(\mathrm{O}) \mathrm{OH}+\mathrm{R}^{\prime} \mathrm{OH} \leftrightarrow \mathrm{R}(\mathrm{O}) \mathrm{OR}^{\prime}+\mathrm{H}_{2} \mathrm{O}$

Assuming that this water does not influence the SOA O:C measurement, esterification leads to an overall Van Krevelen slope of -2 relative to the unreacted hydrocarbon and, by forming a longer-chain species (i.e. an oligomer), a de- crease in vapour pressure despite the loss of functional group (the magnitude of this vapour pressure decrease will depend on the carbon chain length of the molecules involved). Cyclization reactions of hydroxycarbonyl species to form cyclic hemiacetals followed by dehydration to form a dihydrofuran also involve loss of water molecules, again leading to a shift in the Van Krevelen slope towards steeper values. However, such reactions do not lead to oligomerization, and thus the volatility of the dihydrofuran product may be substantially higher than the cyclic hemiacetal. The increased vapour pressure could lead to evaporation of the dihydrofuran, which could undergo further gas-phase processing and, potentially, re-condensation as a more oxidized species. Ultimately, if the dihydrofuran does not remain or end up back in the particle, the Van Krevelen slope of the SOA will be unaffected. It is worth noting that such dehydration reactions will lead to a decrease in the observed SOA O:C, and could provide an explanation for the model over-estimate. Altogether, consideration of the observations and the model results suggest that condensed-phase reactions occur that alter not only the apparent volatility of the SOA species, but also their atomic composition. However, it is possible that a bias against detection of hydroperoxides could also have influenced the observed Van Krevelen slope. Addition of hydroperoxides should yield a slope of 0 . Thus, if hydroperoxides are primarily detected following loss of $-\mathrm{OOH}$, the observed slope would be shifted towards more negative values. To the extent that this occurs, the need to invoke condensed phase reactions to explain the differing indications of functional group addition would be lessened.

Under high- $\mathrm{NO}_{\mathrm{x}}$ conditions, the model $\triangle \mathrm{LVP}$ values ranged from 1.46 to 2.06 (or 1.46 to 1.80 if cyclododecane is excluded). Interestingly, these values are significantly larger than that associated with organonitrate addition $(\Delta \mathrm{LVP}=0.74)$ even though the best-fit $P_{\text {func }}$ array indicates a substantial fraction of reactions add up to 3 or 4 oxygen atoms per reaction, which is consistent with nitrate addition. The mean H-loss-per-O added ranged from 1.25 to 1.83 , also significantly larger than expected if nitrate functional group addition dominates $(-0.33)$. Again, these results suggest that condensed phase reactions are altering the observed SOA properties, and thus the interpretation of the SOM best-fit parameters. As with the low- $\mathrm{NO}_{\mathrm{x}}$ case, condensed phase reactions that make the Van Krevelen slope more negative (steeper) are suggested to reconcile the observations, expected mechanism and SOM results. In the condensed phase, organonitrates can undergo hydration reactions followed by acid-catalyzed nitrate loss to form alcohols. However, such reactions are unlikely under the very low $\mathrm{RH}$ conditions of these experiments, and furthermore would move the slope in the wrong direction (i.e. towards zero). Esterification (dehydration) reactions may also be occurring in the high- $\mathrm{NO}_{\mathrm{x}}$ particles, moving the slope towards more negative values and, likely, decreasing the apparent volatility of the condensed species. Taken together, the low and high- $\mathrm{NO}_{\mathrm{x}}$ 

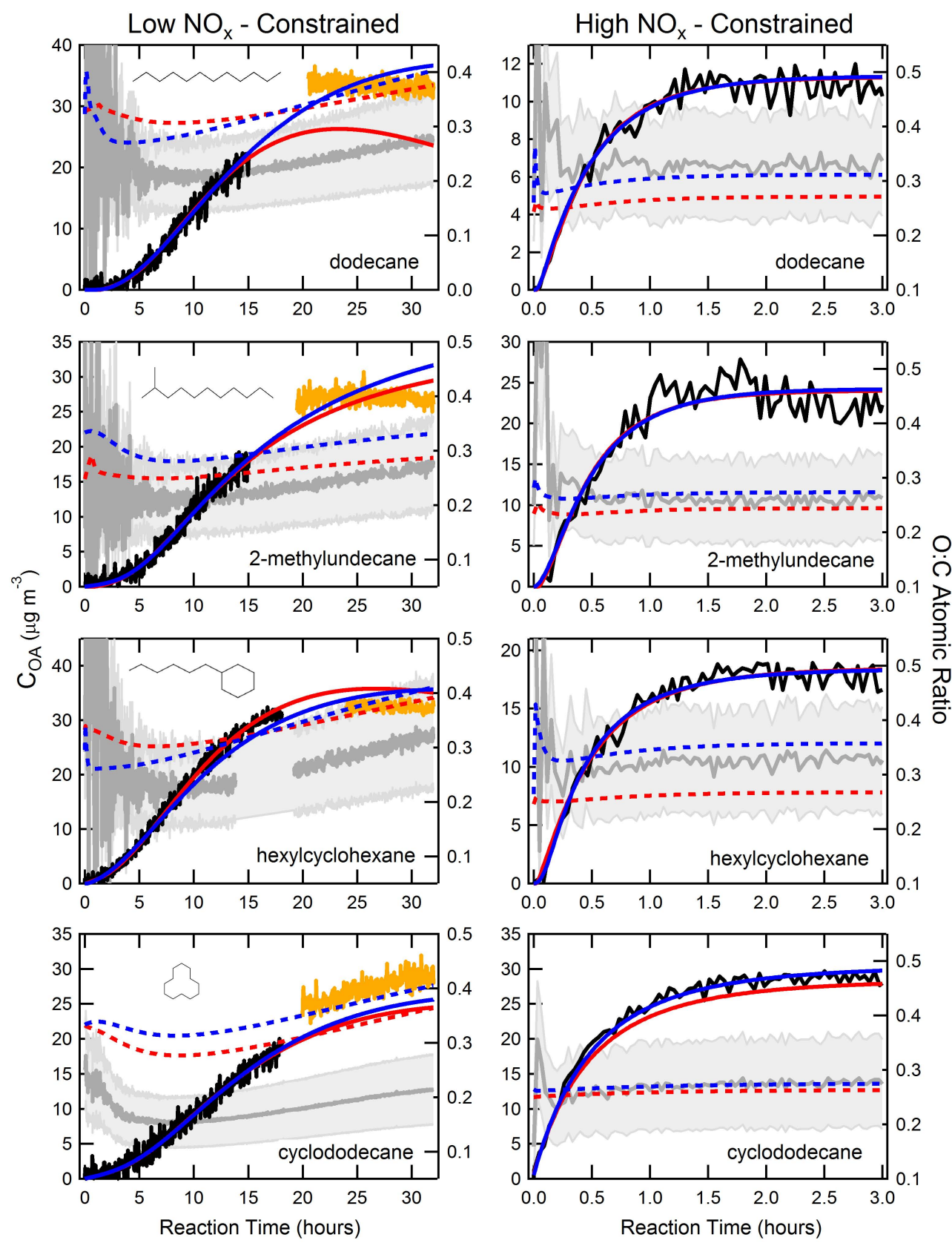

$$
\begin{array}{rlr|}
\hline \text { Observations: }-C_{\mathrm{OA}} & \text { Model: } & P_{\text {frag }}=c_{\text {frag }} \times N_{\mathrm{O}}:-C_{\mathrm{OA}} ; \cdots-\cdots: \mathrm{O} \\
-\mathrm{O}: \mathrm{C} & P_{\mathrm{frag}}=(\mathrm{O}: \mathrm{C})^{m_{\mathrm{frag}}}:-C_{\mathrm{OA}} ; \cdots \mathrm{O}: \mathrm{C}
\end{array}
$$

Fig. 8. Same as Fig. 1, but where the high-NO $\mathrm{N}_{\mathrm{x}}$ and low- $-\mathrm{NO}_{\mathrm{x}} c_{\text {frag }}$ and $m_{\text {frag }}$ parameters have been constrained; see text for details.

results illustrate the broader point that interpretation of Van Krevelen diagrams in terms of how the SOA composition relates to the associated gas-phase composition is not necessarily straightforward since the measurements may likely be affected by condensed phase reactions. This conclusion is consistent with the findings of Craven et al. (2012), who determined that movement between the different identified SOA "factors" occurs along multiple Van Krevelen slopes.
When interpreting the best-fit SOM parameters in terms of chemical mechanisms, as above, it is important to consider the robustness of the fit parameters. This is examined here by re-fitting the SOM to observations of $C_{\mathrm{OA}}$ only (as opposed to $C_{\mathrm{OA}}$ and O:C), but where the $P_{\text {frag }}$ parameters (i.e. $c_{\text {frag }}$ and $m_{\text {frag }}$ ) for the high-NO $\mathrm{NO}_{\mathrm{x}}$ reactions are constrained to be equal to the best-fit values from the low- $\mathrm{NO}_{\mathrm{x}}$ reactions, and vice versa. The extent to which the constrained $c_{\text {frag }}$ and 

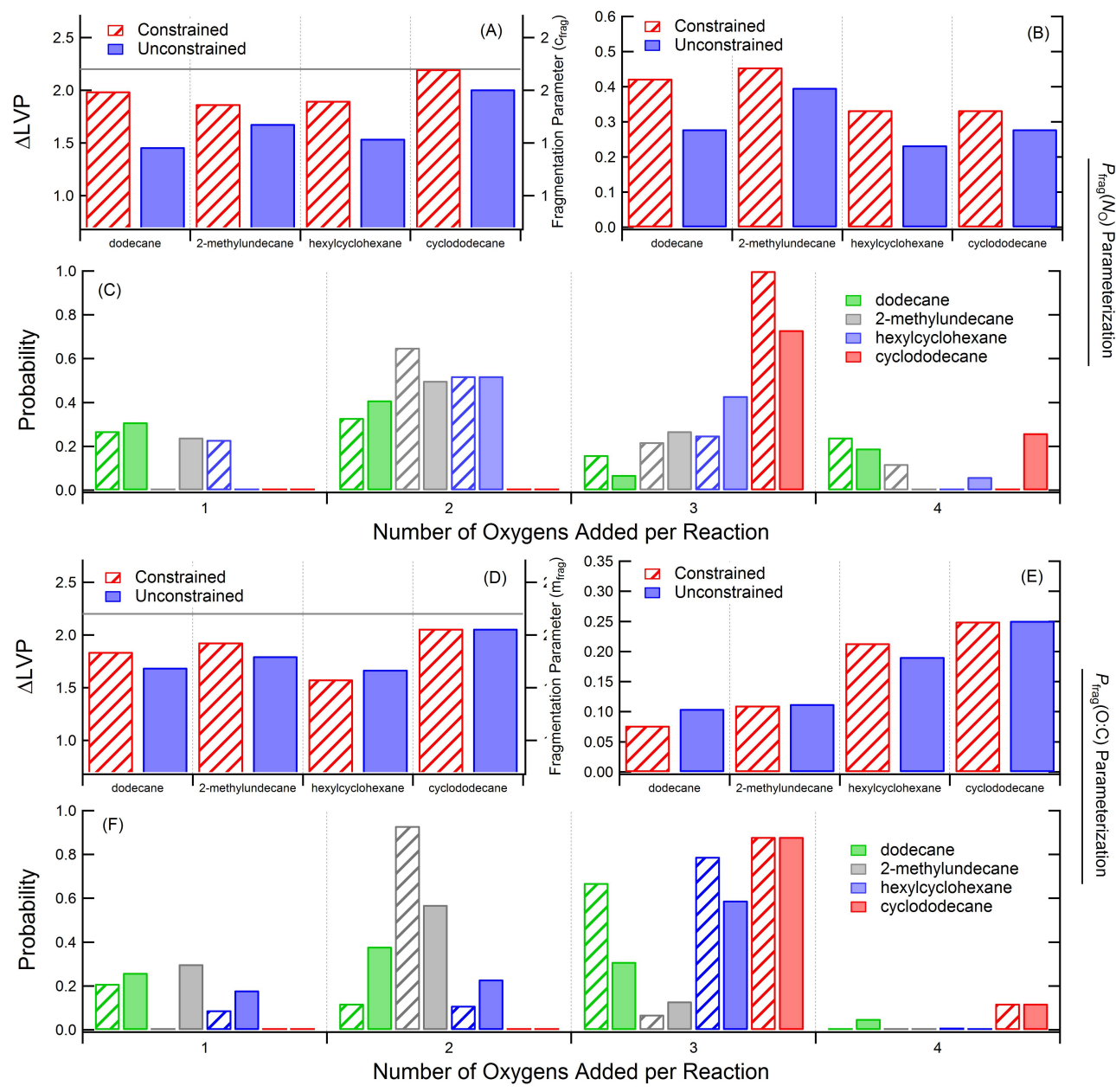

Fig. 9. Best-fit SOM parameters for dodecane, 2-methylundecane, hexylcyclohexane, and cyclodecane under high- $\mathrm{NO}_{\mathrm{x}}$ conditions for both the overall best-fit (solid bars, as in Fig. 2) and the best-fit when the $c_{\text {frag }}$ and $m_{\text {frag }}$ parameters are constrained to be equal to the low-NO overall best-fit values (hashed bars). Results are shown for both the $P_{\text {frag }}\left(N_{\mathrm{O}}\right)(\mathbf{A}-\mathbf{C})$ and $P_{\text {frag }}(\mathrm{O}: \mathrm{C})$ (D-F) parameterizations and include (A and D) $\triangle \mathrm{LVP},(\mathbf{B}$ and $\mathbf{E})$ the fragmentation parameter, and $(\mathbf{C}$ and $\mathbf{F})$ the oxygen addition array. The constrained model was fit only to the observed $C_{\mathrm{OA}}$. The grey line in (A) and (D) indicates the upper-limit constraint on $\triangle \mathrm{LVP}$.

$m_{\text {frag }}$ values differ from the best-fit values differs for each alkane, although in general the constrained high- $\mathrm{NO}_{\mathrm{x}} c_{\mathrm{frag}}$ is larger (and $m_{\text {frag }}$ smaller) compared to the overall best-fit, while for low- $\mathrm{NO}_{\mathrm{x}}$ reactions the opposite is true (Table 2). In most cases, it is still possible to fit the SOM to the observed $C_{\mathrm{OA}}$ growth, although there are a few exceptions where the $C_{\mathrm{OA}}$ is under-predicted after fitting (Fig. 8). In general, the extent to which the best-fit $\triangle \mathrm{LVP}$ and $P_{\text {func }}$ array differ between the constrained and overall fit depends on how different the $c_{\text {frag }}$ and $m_{\text {frag }}$ parameters are. For the high- $\mathrm{NO}_{\mathrm{x}}$ reactions, many of the resulting $\triangle \mathrm{LVP}$ values for the constrained fits are increased to offset the greater fragmentation, while, importantly, the oxygen distributions are reasonably similar between the constrained and overall best-fit (Fig. 9). The predicted $\mathrm{O}: \mathrm{C}$ for the constrained fit does not match the observations quite as well as the overall best-fit (although remaining within the $\pm 30 \%$ uncertainty for all cases; Fig. 8). For the low- $\mathrm{NO}_{\mathrm{x}}$ reactions, some of the resulting $\triangle \mathrm{LVP}$ values for the constrained fits are decreased, although for many cases the differences are small, while the oxygen distributions are generally unchanged (Fig. 10). This comparison illustrates that the $\Delta \mathrm{LVP}$ and $P_{\text {frag }}$ parameters can have compensating effects, which indicates that care must be taken in their interpretation. Nonetheless, the results from the constrained and overall best-fits are sufficiently similar that the general conclusions reached above are unchanged.

\section{Summary and conclusions}

For a comprehensive series of SOA formation experiments from photooxidation of four $N_{\mathrm{C}}=12$ alkanes, two straight chain and two ring-containing, observations indicate that the SOA yield is larger for these compounds under low- vs. high$\mathrm{NO}_{\mathrm{x}}$ conditions, with the exception of cyclododecane. The 

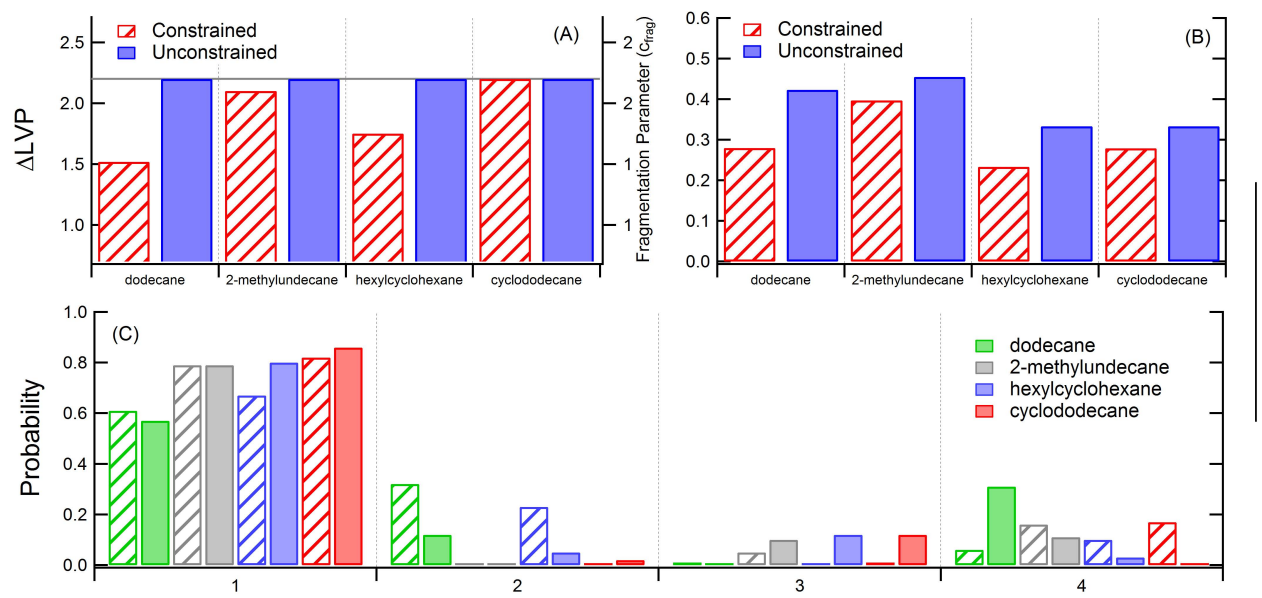

Number of Oxygens Added per Reaction
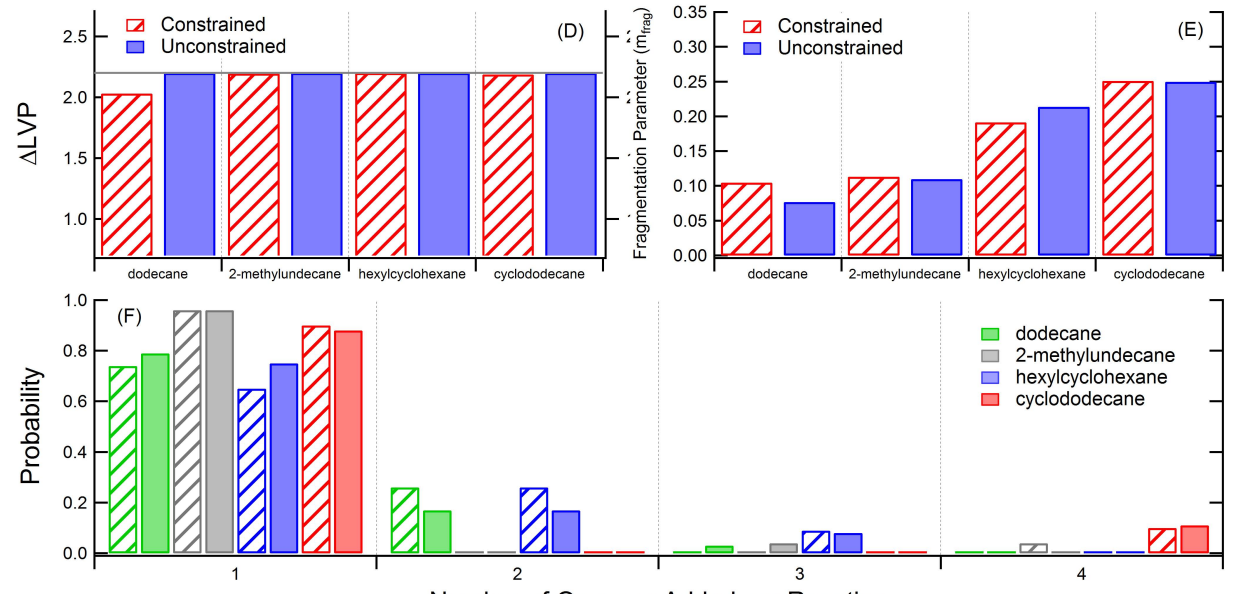

Number of Oxygens Added per Reaction

Fig. 10. Best-fit SOM parameters for dodecane, 2-methylundecane, hexylcyclohexane, and cyclodecane under low- $\mathrm{NO}_{\mathrm{x}}$ conditions for both the overall best-fit (solid bars, as in Fig. 2) and the best-fit when the $c_{\text {frag }}$ and $m_{\text {frag }}$ parameters are constrained to be equal to the high-NO overall best-fit values (hashed bars). Results are shown for both the $P_{\text {frag }}\left(N_{\mathrm{O}}\right)(\mathbf{A}-\mathbf{C})$ and $P_{\text {frag }}(\mathrm{O}: \mathrm{C})$ (D-F) parameterizations and include (A and D) $\triangle \mathrm{LVP},(\mathbf{B}$ and $\mathbf{E})$ the fragmentation parameter, and $(\mathbf{C}$ and $\mathbf{F})$ the oxygen addition array. The constrained model was fit only to the observed $C_{\mathrm{OA}}$. The grey line in (A) and (D) indicates the upper-limit constraint on $\triangle \mathrm{LVP}$.

$\mathrm{O}: \mathrm{C}$ atomic ratio is generally similar between high- and low$\mathrm{NO}_{\mathrm{x}}$, although the low- $\mathrm{NO}_{\mathrm{x}}$ experiments exhibit a continuous increase in $\mathrm{O}: \mathrm{C}$ as oxidation proceeds. This difference results primarily from the differing oxidation conditions: the $[\mathrm{OH}]$ during low- $\mathrm{NO}_{\mathrm{x}}$ experiments was approximately constant around $2 \times 10^{6}$ molecules $\mathrm{cm}^{-3}$, whereas the $[\mathrm{OH}]$ during high- $\mathrm{NO}_{\mathrm{x}}$ experiments started higher but rapidly decayed due to efficient photolysis of the $\mathrm{OH}$ precursor (HONO).

The observed $C_{\mathrm{OA}}$ temporal growth curves have been fit to the statistical oxidation model (Cappa and Wilson, 2012) to derive values for the mean decrease in volatility per oxygen added ( $\triangle \mathrm{LVP})$, the probability of fragmentation and the distribution of oxygens added per reaction. In general, there is excellent model/measurement agreement in terms of the time-evolution of the $C_{\mathrm{OA}}$. This work demonstrates that the use of a kinetic, multi-generation model to represent SOA formation during photooxidation can provide insights into the SOA formation process and facilitate the interpretation of smog chamber observations.

Acknowledgements. This work was supported by the National Science Foundation (ATM-1151062) and the Department of Energy (DE-SC0006626).

Edited by: F. Keutsch

\section{References}

Aiken, A. C., DeCarlo, P. F., and Jimenez, J. L.: Elemental analysis of organic species with electron ionization highresolution mass spectrometry, Anal. Chem., 79, 8350-8358, doi:10.1021/ac071150w, 2007.

Aiken, A. C., Decarlo, P. F., Kroll, J. H., Worsnop, D. R., Huffman, J. A., Docherty, K. S., Ulbrich, I. M., Mohr, C., Kimmel, 
J. R., Sueper, D., Sun, Y., Zhang, Q., Trimborn, A., Northway, M., Ziemann, P. J., Canagaratna, M. R., Onasch, T. B., Alfarra, M. R., Prevot, A. S. H., Dommen, J., Duplissy, J., Metzger, A., Baltensperger, U., and Jimenez, J. L.: O/C and OM/OC ratios of primary, secondary, and ambient organic aerosols with highresolution time-of-flight aerosol mass spectrometry, Environ. Sci. Technol., 42, 4478-4485, doi:10.1021/es703009q, 2008.

Aumont, B., Szopa, S., and Madronich, S.: Modelling the evolution of organic carbon during its gas-phase tropospheric oxidation: development of an explicit model based on a self generating approach, Atmos. Chem. Phys., 5, 2497-2517, doi:10.5194/acp-52497-2005, 2005.

Barsanti, K. C., Smith, J. N., and Pankow, J. F.: Application of the $\mathrm{np}+\mathrm{mP}$ modeling approach for simulating secondary organic particulate matter formation from $\alpha$-pinene oxidation, Atmos. Environ., 45, 6812-6819, doi:10.1016/j.atmosenv.2011.01.038, 2011.

Cappa, C. D., and Wilson, K. R.: Multi-generation gas-phase oxidation, equilibrium partitioning, and the formation and evolution of secondary organic aerosol, Atmos. Chem. Phys., 12, 9505-9528, doi:10.5194/acp-12-9505-2012, 2012.

Chhabra, P. S., Flagan, R. C., and Seinfeld, J. H.: Elemental analysis of chamber organic aerosol using an aerodyne high-resolution aerosol mass spectrometer, Atmos. Chem. Phys., 10, 4111-4131, doi:10.5194/acp-10-4111-2010, 2010.

Cocker, D. R., Flagan, R. C., and Seinfeld, J. H.: State-of-theart chamber facility for studying atmospheric aerosol chemistry, Environ. Sci. Technol., 35, 2594-2601, doi:10.1021/es0019169, 2001.

Compernolle, S., Ceulemans, K., and Müller, J. F.: EVAPORATION: a new vapour pressure estimation method for organic molecules including non-additivity and intramolecular interactions, Atmos. Chem. Phys., 11, 9431-9450, doi:10.5194/acp-119431-2011, 2011.

Craven, J. S., Yee, L. D., Ng, N. L., Canagaratna, M. R., Loza, C. L., Schilling, K. A., Yatavelli, R. L. N., Thornton, J. A., Ziemann, P. J., Flagan, R. C., and Seinfeld, J. H.: Analysis of secondary organic aerosol formation and aging using positive matrix factorization of high-resolution aerosol mass spectra: application to the dodecane low-NO $\mathrm{NO}_{\mathrm{x}}$ system, Atmos. Chem. Phys., 12, 1179511817, doi:10.5194/acp-12-11795-2012, 2012.

DeCarlo, P. F., Kimmel, J. R., Trimborn, A., Northway, M. J., Jayne, J. T., Aiken, A. C., Gonin, M., Fuhrer, K., Horvath, T., Docherty, K. S., Worsnop, D. R., and Jimenez, J. L.: Field-deployable, high-resolution, time-of-flight aerosol mass spectrometer, Anal. Chem., 78, 8281-8289, doi:10.1021/ac061249n, 2006.

Donahue, N. M., Robinson, A. L., Stanier, C. O., and Pandis, S. N.: Coupled partitioning, dilution, and chemical aging of semivolatile organics, Environ. Sci. Technol., 40, 2635-2643, doi:10.1021/es052297c, 2006.

Donahue, N. M., Kroll, J. H., Pandis, S. N., and Robinson, A. L.: A two-dimensional volatility basis set - Part 2: Diagnostics of organic-aerosol evolution, Atmos. Chem. Phys., 12, 615-634, doi:10.5194/acp-12-615-2012, 2012.

Heald, C. L., Kroll, J. H., Jimenez, J. L., Docherty, K. S., DeCarlo, P. F., Aiken, A. C., Chen, Q., Martin, S. T., Farmer, D. K., and Artaxo, P.: A simplified description of the evolution of organic aerosol composition in the atmosphere, Geophys. Res. Lett., 37, L08803, doi:10.1029/2010g1042737, 2010.
Jimenez, J. L., Canagaratna, M. R., Donahue, N. M., Prevot, A. S. H., Zhang, Q., Kroll, J. H., DeCarlo, P. F., Allan, J. D., Coe, H., Ng, N. L., Aiken, A. C., Docherty, K. S., Ulbrich, I. M., Grieshop, A. P., Robinson, A. L., Duplissy, J., Smith, J. D., Wilson, K. R., Lanz, V. A., Hueglin, C., Sun, Y. L., Tian, J., Laaksonen, A., Raatikainen, T., Rautiainen, J., Vaattovaara, P., Ehn, M., Kulmala, M., Tomlinson, J. M., Collins, D. R., Cubison, M. J., Dunlea, E. J., Huffman, J. A., Onasch, T. B., Alfarra, M. R., Williams, P. I., Bower, K., Kondo, Y., Schneider, J., Drewnick, F., Borrmann, S., Weimer, S., Demerjian, K., Salcedo, D., Cottrell, L., Griffin, R., Takami, A., Miyoshi, T., Hatakeyama, S., Shimono, A., Sun, J. Y., Zhang, Y. M., Dzepina, K., Kimmel, J. R., Sueper, D., Jayne, J. T., Herndon, S. C., Trimborn, A. M., Williams, L. R., Wood, E. C., Middlebrook, A. M., Kolb, C. E., Baltensperger, U., and Worsnop, D. R.: Evolution of organic aerosols in the atmosphere, Science, 326, 1525-1529, doi:10.1126/science.1180353, 2009.

Kanakidou, M., Seinfeld, J. H., Pandis, S. N., Barnes, I., Dentener, F. J., Facchini, M. C., Van Dingenen, R., Ervens, B., Nenes, A., Nielsen, C. J., Swietlicki, E., Putaud, J. P., Balkanski, Y., Fuzzi, S., Horth, J., Moortgat, G. K., Winterhalter, R., Myhre, C. E. L., Tsigaridis, K., Vignati, E., Stephanou, E. G., and Wilson, J.: Organic aerosol and global climate modelling: a review, Atmos. Chem. Phys., 5, 1053-1123, doi:10.5194/acp-5-1053-2005, 2005.

Lane, T. E., Donahue, N. M., and Pandis, S. N.: Simulating secondary organic aerosol formation using the volatility basis-set approach in a chemical transport model, Atmos. Environ., 42, 7439-7451, doi:10.1016/j.atmosenv.2008.06.026, 2008.

Lim, Y. B. and Ziemann, P. J.: Effects of Molecular Structure on Aerosol Yields from $\mathrm{OH}$ Radical-Initiated Reactions of Linear, Branched, and Cyclic Alkanes in the Presence of $\mathrm{NO}_{\mathrm{X}}$, Environ. Sci. Technol., 43, 2328-2334, doi:10.1021/es803389s, 2009.

Loza, C. L., Chhabra, P. S., Yee, L. D., Craven, J. S., Flagan, R. C., and Seinfeld, J. H.: Chemical aging of m-xylene secondary organic aerosol: laboratory chamber study, Atmos. Chem. Phys., 12, 151-167, doi:10.5194/acp-12-151-2012, 2012.

Odum, J. R., Hoffmann, T., Bowman, F., Collins, D., Flagan, R. C., and Seinfeld, J. H.: Gas/particle partitioning and secondary organic aerosol yields, Environ. Sci. Technol., 30, 2580-2585, doi:10.1021/es950943+, 1996.

Pankow, J. F.: An absorption-model of the gas aerosol partitioning involved in the formation of secondary organic aerosol, Atmos. Environ., 28, 189-193, doi:10.1016/1352-2310(94)900949, 1994.

Pankow, J. F. and Asher, W. E.: SIMPOL.1: a simple group contribution method for predicting vapor pressures and enthalpies of vaporization of multifunctional organic compounds, Atmos. Chem. Phys., 8, 2773-2796, doi:10.5194/acp-8-27732008, 2008.

Robinson, A. L., Donahue, N. M., Shrivastava, M. K., Weitkamp, E. A., Sage, A. M., Grieshop, A. P., Lane, T. E., Pierce, J. R., and Pandis, S. N.: Rethinking organic aerosols: Semivolatile emissions and photochemical aging, Science, 315, 1259-1262, doi:10.1126/science.1133061, 2007.

Valorso, R., Aumont, B., Camredon, M., Raventos-Duran, T., Mouchel-Vallon, C., Ng, N. L., Seinfeld, J. H., Lee-Taylor, J., and Madronich, S.: Explicit modelling of SOA formation from alpha-pinene photooxidation: sensitivity to vapour pressure esti- 
mation, Atmos. Chem. Phys., 11, 6895-6910, doi:10.5194/acp11-6895-2011, 2011.

Yee, L. D., Craven, J. S., Loza, C. L., Schilling, K. A., Ng, N. L., Canagaratna, M. R., Ziemann, P. J., Flagan, R. C., and Seinfeld, J. H.: Secondary organic aerosol formation from Low-NO Photooxidation of Dodecane: Evolution of Multigeneration GasPhase Chemistry and Aerosol Composition, J. Phys. Chem. A, 116, 6211-6230, doi:10.1021/jp211531h, 2012.

Zhang, Q., Jimenez, J. L., Canagaratna, M. R., Allan, J. D., Coe, H., Ulbrich, I., Alfarra, M. R., Takami, A., Middlebrook, A. M., Sun, Y. L., Dzepina, K., Dunlea, E., Docherty, K., DeCarlo, P. F., Salcedo, D., Onasch, T., Jayne, J. T., Miyoshi, T., Shimono, A., Hatakeyama, S., Takegawa, N., Kondo, Y., Schneider, J., Drewnick, F., Borrmann, S., Weimer, S., Demerjian, K., Williams, P., Bower, K., Bahreini, R., Cottrell, L., Griffin, R. J., Rautiainen, J., Sun, J. Y., Zhang, Y. M., and Worsnop, D. R.: Ubiquity and dominance of oxygenated species in organic aerosols in anthropogenically-influenced Northern Hemisphere midlatitudes, Geophys. Res. Lett., 34, L13801, doi:10.1029/2007GL029979, 2007. 